\title{
THE FOURTH PACIFIC REGIONAL WOOD ANATOMY CONFERENCE
}

\section{'New Horizons in Wood Anatomy on the Threshold of a new Millennium'}

\author{
Meeting of the IAWA Pacific Regional Group and IUFRO S 5.01 (Wood Quality) \\ organized by the Department of Forest Products \& Technology, \\ Chonnam National University, Kwangju 500-757, South Korea \\ October 26-29, 1998
}

Conveners: Dr. Yoon Soo Kim, Dr. Sang Jin Park and Dr. Young Geun Eom

\section{ABSTRACTS OF PAPERS AND POSTERS}

Tatiana V. Arsenieva: Botanical Museum, Komarov Botanical Institute of the Russian Academy of Sciences, Prof. Popov Street 2, St. Petersburg 197 376, Russia. Systematic wood and bark anatomy of Taxodiaceae. - (Paper)

The family Taxodiaceae is one of the most ancient of the modern conifers. The wood and bark structure of young branches (1-5 years old) of ten species belonging to nine genera of Taxodiaceae are described. This study allows to evaluate microstructural characteristics for their diagnostic value. Altogether 60 wood and bark anatomical characters were studied.

Presence or absence of secretory cavities of phloem coincides with a division of this family into tribes. Dimensions of these cavities and the presence or absence of epithelial cells and their numbers allows identification to genera and often to species.

Shape of the pith and the ratio of conducting to unconducting phloem, and the relative diameters of phloem, xylem and pith are also important characters. Pith shape should be studied in 2-years-old branches only. All the other characters are independent of the age of the samples.

Tatiana V. Arsenieva: Botanical Museum, Komarov Botanical Institute, Prof. Popov Street 2, St. Petersburg 197 376, Russia. - Peculiarities of the wood structure and life-forms of Juniperus communis on the Kola Peninsula. - (Poster)

Juniperus communis L. has a wide distribution area and shows a diversity of life forms that are correlated with conditions of the growth.

On the Kola Peninsula the life form of $J$. communis depends on altitude. Near the seashore it is a tree, at $200 \mathrm{~m}$ above sea level a 3-5-stemmed shrub, at $400 \mathrm{~m}$ above sea level a multi-stemmed shrub, and at $700 \mathrm{~m}$ above sea level a trailing shrub. The life form can be regarded as an adaptation and it is of interest to study changes in wood structure.

Conducting and mechanical tissues hardly vary in their dimensions, but the banded parenchyma varies with altitude and the volume of rays decreases with increasing altitude. Dimensions of ray cells change with increasing altitude to a considerable degree. In conclusion, we can note the stability of conducting and mechanical functions of wood of Juniperus communis on the Kola Peninsula and the reduction of the storage function with increasing altitude and reduced plant size. 
T. Awano, K. Takabe \& M. FujtTa: Division of Forest and Biomaterials Science, Graduate School of Agriculture, Kyoto University, Kyoto 606-8502, Japan. - Localization of glucuronoxylans in Japanese beech visualized by immunogold-labelling. - (Poster)

Glucuronoxylans (GXs) are the main hemicellulosic component of hardwood in which they account for $20-35 \%$ of the woody tissue. However, precise localization of GXs in the cell wall has not been shown. The aim of this study is (1) to prepare the specific antiserum against GXs, (2) to visualize the GXs distribution in woody tissue (Japanese beech) by immunogold-labelling, and (3) to discuss the mode of GXs deposition during cell wall formation in wood. ELISA and competitive inhibition tests revealed that the antiserum prepared against GXs could bind specifically to the beta 1-4 linkage of GXs. Therefore, the antiserum was used for immunogold-labelling to investigate the localization of GXs in Japanese beech. The immunogold labellings of GXs were found only in secondary walls of xylem elements, i.e., vessel elements, fibers, axial parenchyma and ray parenchyma. There were hardly any labellings found in the cells during expansion growth. In mature cells, gold particles were evenly distributed throughout secondary wall, except for the outer part of $S_{1}$ layer in which labellings were less abundant. Labelling density (number of gold particles per unit of cell wall area) in $S_{1}$ and $S_{2}$ layers increased during cell wall formation. This suggests that GXs, once secreted into extracellular space, could penetrate through the cell wall layer. In conclusion, GXs start to deposit in the middle of the $S_{1}$ layer formation and penetrate into the secondary wall except for the outer part of the $S_{1}$ layer during cell wall formation.

PIETER BAAS ${ }^{1}$ \& ElisAbeth A. WHEELER ${ }^{2}:{ }^{1}$ Rijksherbarium/Hortus Botanicus, Leiden University, P.O. Box 9514, 2300 RA Leiden, The Netherlands; ${ }^{2}$ Department of Wood and Paper Science, North Carolina State University, P.O. Box 8005, Raleigh, NC 27695-8005, USA. - Wood structure of Southeast Asian timbers - The PROSEA woods reviewed. - (Paper)

The timber volumes in the PROSEA (Plant Resources of South-East Asia) Handbook series provide a comprehensive overview of the structure and properties of the (potentially) commercial woods from one of the three main tropical regions of the world. Altogether timber species from well over 400 tree genera are described in detail in three volumes: major commercial species (47 genera); minor commercial timbers (54 genera); and lesser known genera (295 genera). The incidence of specific wood anatomical features that are known to effect various end-use properties in these timbers or are important in tree biology (such as vessel diameter and frequency, type of vessel perforations, tyloses and gums, fiber wall thickness, parenchyma abundance and distribution, septate fibers, incidence of broad rays, and silica bodies) have been analyzed and compared with data from a large sample of timbers from the North temperate zone and a sample of over 5000 woods from all over the world in the OPCN database maintained at North Carolina State University.

The wood structure and property spectrum of SE Asian commercial timbers agrees closely with general spectra for tropical woods. There is an interesting and significant shift of the structural spectra from the major, via the minor, to the lesser-known tim- 
bers. This shift has little to do with the wood properties desired by end-users, but can largely be explained by ecological factors. Most major commercial species are traditionally from emergent trees in lowland rain forest. The lesser known species include many species of smaller stature from the lower canopies in the lowland forest or from (sub)montane forests. From other studies it is known that tree size and altitudinal distribution correlates significantly with features such as vessel diameter, vessel density, incidence of scalariform vessel perforations and various other features analyzed.

It is suggested to use the wealth of information in the PROSEA timber handbooks to help establish a better informed strategy for sustainable forestry, including enrichment planting with native species of once logged-over forests.

Hyeun-Jong BaE ${ }^{1}$, Louis-Philippe Vezina ${ }^{1}$, Ginette Turcotte ${ }^{2} \&$ Yoon Soo Kim ${ }^{3}$ : ${ }^{1}$ Department de Phytologie; ${ }^{2}$ Department des Sciences des Aliments et de Nutrition, Université Laval, Sainte-Foy, Québec, Canada G1K 7P4; ${ }^{3}$ Department of Forest Products and Technology, Chonnam National University, Kwangju 500-757, Korea. Cytochemical localization of $\beta$-1,4-glucans in plant cell wall using endo- and exoglucanase-gold complexes. - (Poster)

For cellulases, it is assumed that the active site involves a definite number of cellulose subunits, each of which specifically interacts with a certain unit in a cellulose polymeric substrate. The sites of enzymatic reactions on thin sections of plant cell walls were visualized by an enzyme-gold complex in the transmission electron microscope (TEM). The effect of the presence of lignin and hemicellulose in the plant tissue was investigated to characterize the cell surface interactions between the $\beta-1,4-$ glucan substrates and the endo- and exoglucanases during cellulose degradation.

Józef Bednara \& Beata Nieweglowska-Guzik: Department of Plant Anatomy and Cytology, Maria Curie-Sklodowska University Akademicka 19, 20-033 Lublin, Poland. - Pine tree xylem is changed by contaminations with sulphur compounds. - (Poster)

In the vicinity of the Sulphur Mine Tarnobrzeg (Poland) the trees of Pinus sylvestris $\mathrm{L}$. have bushy-like crowns with pathological wood anatomy. The abnormalities are visible in annual ring development and in the features of the xylem elements. Cross and radial sections of sprouts reveal that lenticular, greatly changed xylem areas are located in the earlywood. These areas are composed of changed tracheids and parenchymatic cells. Both lose their prolate shape, becoming short and large. Finally it is difficult to distinguish tracheids and parenchyma because of poor cell wall lignification. Usually changed areas appear in earlywood as the first progeny of spring cambium. Later a gradual reconstruction of normal shape xylem and ray cells takes place but so-called pseudo-rings still exist.

Su Kyoung Chun: Department of Wood Science and Technology, College of Forestry, Kangwon National University, Chunchon 200-701, Korea. - Water flow path in Acer species growing in Korea. - (Paper)

The water moves from roots to leaves thanks to differences in water potentials between adjacent xylem tissues. The flow pathways of water vary according to tree 
species, depending on wood structure. In order to understand and to visualize the flow pathways in some Acer species native to Korea, $1 \%$ acidic dye solution was penetrated into living trees of A. ginnala, A. mono, A. negundo, A. pseudo-sieboldianum, and $A$. palmatum, and the pathways were observed with light microscopy.

Almost the entire xylem was stained with the dye except for a small area near the pith, when examining cross sections with the naked eyes. For all five species, only vessel elements were fully penetrated. Only a little penetration into the adjacent cells such as fibers, axial and ray parenchyma cells, was observed. The radial flow of dye through the rays was negligible. The diffusion of dye into the cells adjacent to vessels was observed at the butt-end soaked in the dye solution during treatment. This result suggests that the rate of water diffusion into vessel-adjacent cells in Acer species is slower than that of other species examined previously.

Woo-Yang Chung \& Seung-Gon Wi: Department of Forest Products and Technology, Chonnam National University, Kwangju 500-757, Korea. - Film formation and acoustical influence of nitro-cellulose and Korean Rhus lacquer on violins. - (Poster)

Nitro-cellulose lacquer has been substituted for traditional coating material, i.e., alcohols and spirit varnishes which had little resistance to wear from rubbing especially for mass-produced violin-type instruments. It can be applied with a spray-gun and dries rapidly with a glass-smooth surface giving a very high shine and durability. However, the liquid cellulose lacquer and the vapor are highly inflammable and toxic. Furthermore its film is too thick and hard for the manufacturing of high-quality instruments. Traditional Korean Rhus lacquer has achieved worldwide fame as a durable film with an elegant appearance.

In the present study, Korean Rhus lacquer as a substitute for nitro-cellulose lacquer was applied to European spruce and hard maple with various annual-ring widths on the single and double side of radially sectioned surfaces. The aspect of film forming and penetration into the wood specimen was examined by optical microscopy and acoustical property changes before and after the coating was investigated by free vibration frequency analysis.

Sprayed cellulose lacquer could not penetrate into the wood cells due to the sealer applied primarily and gave the average total thickness of seven coats as $40 \mu \mathrm{m}$. On the contrary, brushed and rubbed Korean Rhus lacquer filled two to four earlywood tracheids of spruce from the surface and about four cells (including the vessels) in the earlywood of hard maple. However, it could not penetrate into the latewood of both wood species. After four times coating with Korean Rhus lacquer the film was formed about $10 \mu \mathrm{m}$ thick below surface. Double side coating with cellulose lacquer resulted in exclusively the lowest dynamic MOE in both wood species and the internal friction of spruce increased by both lacquers. However, there was no significant change in acoustical properties after varnishing both violin plate materials.

Consequently, Korean Rhus lacquer can be applied to the coating of string instruments of the violin family to enhance the touch and appearance and must be preferred to synthetic lacquera which are hazardous and toxic. 


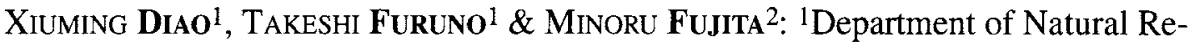
sources Processing Engineering, Faculty of Science and Engineering, Shimane University, Matsue 690-8504, Japan; '2Division of Forest and Biomaterials Science, Graduate School of Agriculture, Kyoto University, Kyoto 606-8502, Japan. - Modeling cross-sectional tracheid shapes based on two-dimensional power spectrum analysis. - (Poster)

This study deals with the quantitative analytical method of cross-sectional tracheid shape based on two-dimensional power spectrum obtained by the fast Fourier transform of cell image. According to the Fourier transform principle, the theoretical analysis was made with an assumption of impulse and rectangular functions for cell wall elements. The error problem is discussed with reference to the cell element dimension and orientation when using the polar coordinate analysis in the frequency domain. The results suggest that the power distribution of cell wall elements in the frequency domain could be estimated with the Lorentz distribution function. The effect of the lower frequency limit on the cell wall dimension and orientation is discussed. Also, it is suggested that the suitable lower frequency limit should at least be larger than the frequency corresponding to the smallest diameter when calculating an angular distribution function of grey levels in frequency images. Based on the theoretically analyzed results, the length ratio of tangential walls to radial walls, as well as an element angle (an angle between radial wall and radial direction), could be obtained from the angular distribution function of grey levels of frequency images as two-dimensional power spectra. Thus, a model of cross-sectional tracheid shapes could be constructed. The results for Japanese red pine (Pinus densiflora Sieb. et Zucc.) and other softwoods demonstrated that the power spectrum analysis could be used to develop a faster and more objective method for determining the model of cross-sectional tracheid shapes.

S. DoI, S. OHTa, Y. KobaYashi \& H. Sasaki: Institute of Wood Technology, Akita Prefectural College of Agriculture, 11-1 Kaieizaka, Noshiro, Akita 016-0876, Japan.Improvement of wood permeability using a micro-biological process - Ecosystems of microbes in sugi (Cryptomeria japonica D. Don) logs and changes of pit membrane of sugi wood samples after ponding. - (Poster)

Currently, incision techniques are applied to get good permeability for the preservation, drying or chemical modification of wood. However, these techniques cannot sufficiently improve permeability because the pit structures which regulate permeability are not degraded. We have been studying a micro-biological process for improving permeability using sugi logs since last year. The methodology of our investigation and the succession of microbes in the ponded logs are presented. The number of bacteria in sapwood and intermediate wood of logs increased immediately after ponding although it did not increase in the heartwood until after 9 months. The dominant species of microbes in logs, anatomical changes of wood and the effects on the permeability of wood will be presented.

Lloyd A. Donaldson \& Adya P. Singh: New Zealand Forest Research Institute Ltd., Private Bag 3020, Rotorua, New Zealand. - Ultrastructure of tracheid cell walls and lignin distribution in radiata pine (Pinus radiata) mild compression wood. - (Paper) 
Interference microscopy was used to determine quantitative variations in lignin concentration in mild compression wood of Pinus radiata. The structure of mild compression wood was also examined by confocal laser scanning microscopy (CLSM), and transmission electron microscopy (TEM).

Two anatomically different samples of mild compression wood were compared with a sample of normal wood. Quantitative interference microscopy provided information on lignin concentration in different regions of the cell wall with values of $26 \%, 46 \%$ and $57 \%$ respectively for the $\mathrm{S}_{2}, \mathrm{~S}_{2 \mathrm{~L}}$ and ccml regions of sample 1 , and $20 \%, 29 \%$ and $46 \%$ for the same regions of sample 2 . Microdensitometry of confocal fluorescence images provided semiquantitative information on the relative lignin distribution based on lignin autofluorescence. Comparison between the two compression wood samples using autofluorescence gave results which were in partial agreement with interference microscopy with respect to the relative lignification levels in the $\mathrm{S}_{2}, \mathrm{~S}_{2 \mathrm{~L}}$ and $\mathrm{ccml}$ regions.

TEM observations revealed evidence for radial striations in the $S_{2}$ region probably representing regions of alternating high and low lignin concentration which may be the precursor to the helical cavities found in severe compression wood. These radial striations typically showed a sinuous and branched structure, extending partly into the $S_{2 L}$ region.

L.A. Donaldson, L. Grace \& N. Cranshaw: New Zealand Forest Research Institute Ltd., Private Bag 3020, Rotorua, New Zealand. - Development of in-vitro tracheary elements studied by confocal microscopy. - (Poster)

Confocal laser scanning microscopy was used to study the development of tracheary elements in xylogenic tissue cultures of Pinus radiata D. Don. Xylogenic cultures are being used by Forest Research as a tool for rapid evaluation of genetically transformed cell lines. Tracheary elements developed after two weeks of culture on solid growth medium from a mixture of meristematic cells, characterized by prominent condensed nuclei, plastids (amyloplasts) and large vacuoles, and xylem mother cells with dense cytoplasm containing an extensive endoplasmic reticulum. Several stages of development could be recognized including elongation, and secondary wall formation. Two types of tracheary elements were observed, one with helically thickened secondary walls and bordered pits, and a second larger cell type with bordered pits but no helical thickenings. Comparison with primary xylem from young shoots indicated that both cell types were intermediate between primary metaxylem and secondary tracheids. Tracheary elements showed autofluorescent secondary walls which also stained positively for lignin with toluidine blue.

DIETER ECKSTEIN \& INGO BURGERT: Institute of Wood Biology, University of Hamburg, Leuschnerstr. 91, D-21031 Hamburg, Germany. - Does the ray tissue contribute to the biomechanics of living trees? - (Paper)

The growth and morphogenesis of trees is influenced by static and dynamic loads. The form of fibers and tracheids and their cell wall structure are optimized to cope with axial stresses. In bended parts of trees also transversal stresses appear. In this case the wood rays, with their radial orientation, might contribute to an enhanced 
radial strength. Observations during a field study, in which deciduous tree species with different anatomical structures have been exposed to defined radial loads, show anatomical alterations implying an adaptation of the ray tissue in response to the radial forces. Additional technological investigations on various deciduous tree species underline the importance of orientation, size, and abundance of wood rays on the transversal strength of living trees.

ARSENIo B. Ella: Materials Properties Evaluation Division, Forest Products Research and Development Institute (FPRDI), Department of Science and Technology (DOST), College, Laguna, Philippines. - Wood anatomy of four strains of giant ipil-ipil (Leucaena leucocephala). - (Paper)

Two trees each of four strains of giant ipil-ipil [Leucaena leucocephala (Lam.) De Wit], viz., K-8, K-21, K-28 and K-67 were used in the study. Anatomical descriptions, including some general characteristics and properties of the wood were based on disc samples taken at breast height (dbh).

Results indicated the difficulty of specific identification of the woods of the four strains based on macro-anatomical structures. Many characteristics are common both in the gross and minute wood features. Some microscopic features, on the other hand, gave slight differences, viz., vessel tangential diameter, length of vessel members and height of multiseriate rays. These observations are not sufficient criteria to pinpoint identification of the strains.

Arsenio B. Ella \& Fernando C. Pitarguen Jr: Forest Products Research and Development Institute (FPRDI), College, Laguna, Philippines. - Identification and end-use characterization of unexploited woody vines based on morphological and anatomical features. - (Paper)

The morphology and wood anatomy of 10 Philippine woody vines were studied to provide data for proper identification and specific end-use. These include: Ichnocarpus frutescens (hingiu); Streptocaulon baumii (hinggiu-kalabau); Entada phaseoloides (gogo); Merremia peltata (bulakan); Smilax bracteata (banot); Anamirta cocculus (bayati); Freycinetia formosana forma banahaensis (vayasubas); Freycinetia vidalii (white vine); Freycinetia merrillii (red vine); and Rourea volubilis (kamagsa). Keys to the species identification were provided based on the diagnostic characters of the leaves and flowers and field characters of stems. Field and herbarium studies were carried out to elucidate the ecology of the species. Morphological characters of the bark were used to distinguish species with overlapping characteristics. Anatomically, the striking features of the vine species are the following; growth rings indistinct; pores extremely small to very small, almost solitary except for gogo which exhibited pore multiples; rays multiseriate ranging from 2 to 23 cells wide. Bayati has the tallest rays, banot has the narrowest and shortest ones. Fibers rage from thick- to very thick-walled. Hinggiu-kalabau has the thickest and vaysubas the thinnest fiber walls. Gogo has the longest fibers and bayati the shortest ones. Vinecraft makers use hinggiu and hinggiu-kalabau to make baskets. Banot and kamagsa are preferred for wall decors because they are soft, and have a fine texture.

For the mouth, handle, and base of baskets, bulakan and bayati are used. Red vine and white vine, on the other hand, are suitable for Christmas decors. 
Young Geun Eom ${ }^{1} \&$ Youn JiB Chung $^{2}:{ }^{1}$ Department of Forest Products, College of Forest Science, Kookmin University, Seoul 136-702, Korea; ${ }^{2}$ Institute of Forest Science, Kookmin University, Seoul 136-702, Korea. - Perforated ray cells in Korean hardwoods. - (Paper)

Approximately 280 Korean hardwood species, covering 61 families and 153 genera, were investigated for the presence of perforated ray cells. Ray cells with perforations were recorded in 17 families, 29 genera, 39 species, and their perforations were generally identical with the types of perforation plates in the vessel elements of the same wood. Perforated ray cells had perforation plates in their radial walls and tangential walls, and appeared sometimes to connect a vessel on one side of a ray with a vessel on the opposite side of that ray in tangential surface. Although perforated ray cells have been known to be mostly confined only to the uniseriate extensions of long rays and uniseriate rays, they were observed in the multiseriate parts and marginal uniseriate parts of rays, uniseriate extensions of rays, and uniseriate rays. Perforated ray cells were usually much larger than the adjacent ray cells, although in some cases they had the same dimensions or were only a little larger than the adjacent cells. Perforated ray cells in Korean hardwood species are not a characteristic feature of particular taxonomic groups because of their irregular occurrence.

Nurgün Erdin, A. Dilek Dogu, S. Nami KarTal \& C. Köse: Department of Forest Biology and Wood Protection Technology, University of Istanbul, Faculty of Forestry, 80895 Bahçeköy, Istanbul, Turkey. — Some anatomical properties and wood density of Ostrya carpinifolia grown in Turkey. - (Paper)

The aim of this study is to determine some important anatomical properties, ovendry and air-dry densities of Ostrya carpinifolia Scop., and get some proposals related to its usage in industry. Three trees were harvested from the West Black Sea region of Turkey; $15 \mathrm{~cm}$ thick discs were cut at $0.30,1.30,3.30,5.30,7.30$ and $9.30 \mathrm{~m}$ of each tree and all measurements were made on these discs.

Vessel number per $\mathrm{mm}^{2}$, vessel diameter, vessel width, vessel wall thickness, fiber diameter, lumen diameter of fibers, wall thickness of fibers, fiber length, type of longitudinal parenchyma cells, vessel pits, type of perforation plates, type of ray cells, height and width of ray cells and ray cell number per $\mathrm{mm}^{2}$ were determined. The variations of these properties among the discs were analyzed among and within the trees.

Tomoyuki FujiI ${ }^{1}$, Sri Nugroho Marsoem ${ }^{2} \&$ Takeshi FujiWara ${ }^{3}:{ }^{1}$ Wood Anatomy Laboratory and ${ }^{3}$ Wood Quality Laboratory, Forestry and Forest Products Research Institute, Tsukuba 350-8687, Japan; ${ }^{2}$ Wood Physics Laboratory, Faculty of Forestry, Gadja Mada University, Bulaksumur, Yogyakarta 55281, Indonesia. - Annual growth rings in mahogany (Swietenia macrophylla) growing in Java. - (Paper)

Plantation-grown trees of mahogany (Swietenia macrophylla King) in Java were pin-marked monthly from August to December in 1996 and sampled on August 7, 1997. Pin-markings were also executed weekly in July, 1997.

Axial parenchyma in marginal bands is $3-6$ cells wide, occasionally associated with vessels inside and with conspicuously narrower vessels outside, and is continu- 
ous concentrically. The growth ring boundaries are marked also by low vessel density just outside the parenchyma bands. Traumatic tissues formed in response to the pinnings were characterized by both callus tissues around each cavity filled with gummy substance and surrounding 2 or 3 tangential bands of traumatic gum ducts embedded in a wide axial parenchyma band. Small druses in crystaliferous cells were frequent in wide axial parenchyma bands, besides common rhomboidal integumented crystals in ray cells.

The outermost mature xylem adjacent to the cambium in the dry season was composed of ground tissue fibers and vessels partially protruding towards the outside, and marginal axial parenchyma bands were not yet formed outside them. In samples pinmarked in the latest dry and/or in rainy seasons, wide traumatic axial parenchyma bands transformed tangentially into 3-6 cells wide bands, although separate normal marginal axial parenchyma bands were clearly recognized inside the samples pinmarked in the mid-rainy season. Consequently, marginal axial parenchyma bands are probably formed during the early rainy season, and those marginal bands in the samples pin-marked in the latest and/or early rainy seasons may possibly be overlapping with traumatic tissues.

Soft-X-ray densitometrical studies showed that the number of the axial parenchyma bands and the fluctuation of the ring width generally coincided with each other within four directions in each disk, and the estimated ages roughly equaled the age of the trees. These results indicate that the marginal axial parenchyma bands are formed annually corresponding to a dry season once a year.

Yoshitake Fujisawa ${ }^{1}$, Ryogo NAKada ${ }^{1} \&$ Yasuhiko Hirakawa ${ }^{2}$ : ${ }^{1}$ Forest Tree Breeding Center, 3809-1 Ishi, Taga, Ibaraki 319-1301, Japan; ${ }^{2}$ Forestry and Forest Products Research Institute, P.O. Box 16, Ibaraki 305-8687, Japan. - Characteristics of ring analysis of progenies artificially mated among sugi (Cryptomeria japonica) local cultivars using the derivative method. - (Poster)

Japanese sugi cedar (Cryptomeria japonica D. Don) is the most important coniferous species in Japan and is utilized for various purposes, especially as construction material. However, a high variability in the wood properties of sugi are recognized as a problem, when used as raw material. Especially, large variations in density from earlywood to latewood within a growth ring are recognized as important problems of wood processing by rotary lathes and planers.

We studied clonal characteristics of transition patterns for variation in density from earlywood to latewood within a growth ring at the mature stage, using soft-X-ray densitometry and a density curve standardized by a relative distance from a terminal within a growth ring, which was named in previous papers 'the relative density curve method'. The relative density curve method was useful to compare the characteristics of transition patterns between growth rings from different clones, but this method was not adapted to the quantitative analysis of that transition pattern within a growth ring. Therefore we considered it too difficult to introduce the family analysis for the transition pattern within a growth ring because we should compare among many growth rings on family analysis. 
On the other hand Panestal et al. and other researchers introduced the numerical derivative method to define growth ring boundaries based on data gathered by soft-Xray densitometry. The numerical derivative method was also useful to estimate the degree of the variation in density from earlywood to latewood within a growth ring. We carried out the analysis variation in density from earlywood to latewood between two typical clones, using the numerical derivative method combined with relative distance from a terminal within a growth ring. Consequently, we succeeded to show clear differences in variation in density from earlywood to latewood within a growth ring between those clones.

M. Fujita, Y. Midorikawa \& Y. Ishida: Division of Forest and Biomaterials Science, Graduate School of Agriculture, Kyoto University, Sakyo-ku, Kyoto 606-8502, Japan. - Fourier transform image analysis for characterization of wood cell structures. - (Paper)

Fourier transform image analysis (FTIA) composed of pre-FFT, FFT and post-FFT procedures was improved for practical use. The major process of the pre-FFT is extraction of specified structural factors, as too many factors such as cell sizes, cell shapes, cell wall thickness, cell arrangements and so on are intermingled in a wood section. On the other hand, the number of structural elements such as tracheids or vessels should be sufficient. Over several hundreds of elements are needed for quantitative analysis. Deformation of elements must be minimized, of course. Mapping methods were devised to overcome the difficulties. The first mapping procedure on a transverse section is the binarization to two regions of cell walls and cell lumens, although cell wall thickness is not so accurate in the procedure. The next one is the shrinking of lumens to a dot. By the procedure distribution of various cells could be purified and then offered to FFT. Cell shapes were extracted by the net mapping on which the wall maps were thinned to one pixel width. When the cell wall thickness is even between neighboring cells, the net maps are regarded to be the network of intercellular layers. Cell wall thickness is extracted by the boundary between walls and lumens. Au-sputter coating on the inner surface of walls was applied to visualize the boundary. On the other hand, polar coordinate analysis was introduced for accurate quantitative evaluation of cell arrangement and cell shapes. Also some troubles accompanied by two-dimensional FFT were verified and improved. When such sequence of FTIA was applied to tracheids of softwoods, the most typical tracheid structures could be reconstructed with the probability distribution.

Takeshi Fujiwara, NaOKi OKada \& Kana Yamashita: Wood Quality Laboratory, Forestry and Forest Products Research Institute, Kukizaki, Ibaraki 305-8687, Japan. - Effects of altitude on radial growth in Abies veitchii and Abies mariesii growing at Mt. Norikura, Central Japan. - (Poster)

Ring width and maximum density were measured in Abies veitchii Lindl. and A. mariesii Masters at five altitudes (1600-2400 m above sea level) on Mt. Norikura, Central Japan, to analyze altitudinal and climatic effects on tree growth.

Mean growth rate was greater at a lower elevation site, probably because of higher summer temperature and earlier cambium reactivation. Size-age relationship estimated 
from ring width suggested that trees at a lower altitude had fewer rings compared to their large diameter than those at a higher altitude. Successive decline of radial growth following vigorous initial growth was observed in the faster grown trees, while growth rate tended to fluctuate around a constant level at higher sites. Thus, individuals at lower altitudes were inferred to have a shorter life cycle as a result of fast growth.

Responses of radial growth to climate were more sensitive at a higher elevation. In the lowest site $(1600 \mathrm{~m})$, neither ring-width nor maximum-density chronologies showed significant correlation with climate data, whereas a significant correlation between chronologies and summer temperature was found in higher sites. Ring-width chronologies in higher sites were positively correlated with the temperature in July and August of the current year. Chronologies of maximum density were correlated with the temperature in April, July, August and September of the current year. Summer precipitation in the growing period did not affect ring width but the maximum density was negatively correlated.

R. Funada, M. Shibagaki, O. Furusawa, H. Miura, K. Fukazawa \& J. Ohtani: Department of Forest Science, Faculty of Agriculture, Hokkaido University, Sapporo 060-8589, Japan.- Arrangement of cytoskeleton in differentiating tracheids visualized by confocal laser scanning microscopy. - (Paper)

The arrangement of cytoskeleton in differentiating tracheids was observed by confocal laser scanning microscopy after immunofluorescence staining. Confocal laser scanning microscopy is a powerful tool for visualizing cytoskeleton in large areas and reconstructing three-dimensional images.

The cortical microtubules in tracheids during formation of the primary wall were not well ordered. The orientation of cortical microtubules changed progressively from longitudinal to transverse as tracheids expanded. During formation of the secondary wall, the orientation of cortical microtubules changed from a flat S-helix to a steep Z-helix and then to a flat S-helix. The actin filaments were axially oriented in fusiform cambial cells and their orientation did not change during primary wall formation. Their axial orientation in differentiating tracheids was retained during formation of the secondary wall. In some of the tracheids, transversely or obliquely oriented actin filaments were observed at the final stage of xylem differentiation. These results indicate that there is no clear relationship in the orientation between cortical microtubules and actin filaments in differentiating tracheids.

IKUO FuRUKaWA: Faculty of Agriculture, Tottori University, Koyama, Tottori 6808533, Japan. - The influence of water dficiency on the formation of wood fibers of Caragana korshinskii planted in the China deserts. - (Paper)

The effect of water deficiency on the formation of secondary xylem of the native leguminous species, planted in the arid region of China for controlling desertification and fixing the shifting sand-dunes, was investigated using light and scanning electron microscopy.

Samples were taken from 8-year-old and 17-year-old plants of Caragana korshinskii, which had been planted under irrigated and non-irrigated conditions at the southeast margin of the Tengeli Desert located near Shapotou, Ning-xia Hui-zu zizhiqu, China. 
Non-irrigated means that the seedlings for the first three years had been grown in a nursery station under irrigated conditions, then transplanted to desert land under nonirrigated conditions, with natural annual precipitation of about $160 \mathrm{~mm}$ during the summer season. Fiber length, vessel element length, fiber wall thickness, and structure were examined.

The water deficiency conditions strongly affected both the enlarging and the wallthickening phases following cell division. The tip-portion of the wood fibers, elongated by intrusive growth, showed a distinct tapering or abrupt narrowing. In addition, the length of the fibers formed under non-irrigated conditions was almost one half of the normal fiber length shown under irrigated conditions. These results suggest that water stress strongly suppressed the intrusive growth and decreased biomass production during the differentiating period of the wood fibers.

Regardless of irrigated conditions, distinct tension wood existed within the secondary xylem of the examined samples. An additional gelatinous layer (G-layer) was observed. Three types of G-layers were noted: unlignified, partially lignified and completely lignified.

Takeshi Furuno \& Xiuming Diao: Department of Natural Resources Processing Engineering, Faculty of Science and Engineering, Shimane University, Matsue 6908504, Japan. - Automatic measurements of vessel lumen shapes and diameters for Papua New Guinea wood species using image analysis. - (Paper)

It is difficult to quantify vessel lumen shapes and diameters as important parameters of anatomical structure with light microscopy. In this study, a circularity index and an aspect ratio were introduced to evaluate the vessel shapes in transverse sections. Tangential Feret's diameters, Heywood diameters, and hydraulic diameters as vessel dimensions were also measured. These parameters were obtained for 80 Papua New Guinea wood species. The frequency distributions of circularity indexes for all species were classified into three basic types; Type A with one peak, Type B with two peaks, and Type $\mathrm{C}$ with more than two peaks. Based on the frequency distributions of circularity indexes, solitary pore ratios could be obtained and they were compared with those obtained with microscopic observations. The results show that there is a good agreement between the two methods for estimating the solitary pore ratios.

Vessel shapes were analyzed quantitatively using the circularity index and aspect ratio. Solitary pores are similar to an ellipse and pore multiples are arranged in the radial direction for the Papua New Guinea wood species analyzed. In addition, tangential Feret's vessel diameters obtained were compared with tangential diameters by microscopic observations. There was a high correlation between tangential Feret's diameters and microscopic diameters. It is suggested that the image processing technique could be used to measure the tangential Feret's vessel diameters for estimating the tangential diameters.

Peter Gasson: Jodrell Laboratory, Royal Botanic Gardens, Kew, Richmond, Surrey, TW9 3AB, United Kingdom. - Wood anatomy and its bearing on generic and tribal delimitation in Leguminosae. - (Paper)

Leguminosae constitute a large family divided into three subfamilies (sometimes raised to family level) and many tribes. Polhill's synopsis of genera (1994, in Phyto- 
chemical Dictionary of the Leguminosae, Chapman \& Hall) divides Mimosoideae into 65 genera in 5 tribes, Caesalpinioideae into 153 genera in 4 tribes and Papilionoideae into c. 450 genera in 30 tribes. A high proportion of genera are woody, and many produce valuable timber. Recognizing legume wood is usually straightforward, but distinguishing between some genera can be difficult or impossible, because many are similar anatomically, even when in separate tribes. Several examples are used here to demonstrate the strong support that wood anatomy can give to the separation or combination of genera, and the positioning of genera in tribes.

Hardwickia and Kingiodendron, once combined in Hardwickia, have long been separate, the latter having normal axial canals, although they both belong in the same tribe (Detarieae, Caesalpinioideae). Colophospermum and Hardwickia, from Africa and India, respectively, have recently been combined, creating some controversy. Swartzia (c. 130 species in the New World) is thought by some authorities to be separate from two African species (Bobgunnia), although their wood is anatomically very similar. Some long-recognized tribes are now considered to be polyphyletic, and there are strong similarities between the wood anatomy of genera currently placed in separate tribes, e.g. Baphiopsis (Swartzieae) and Baphia (Sophoreae) and some genera in Dalbergieae with Sophoreae (all Papilionoideae). Tribal delimitations and generic relationships are also in flux in Caesalpinioideae, e.g. in Detarieae and Amherstieae, once separated but now combined.

Wood anatomy can contribute significantly to taxonomic conclusions in all these groups at both generic and tribal level. Having surveyed in the Papilionoideae most Sophoreae and Swartzieae genera, I am currently studying Dipterygeae and Dalbergieae, and some genera in Detarieae (Caesalpinioideae).

Kyeong SiK HaN ${ }^{1}$ \& Woong-Young SoH ${ }^{2}:{ }^{1}$ Department of Biology, Woosuk University, Samrae-Up, Wanju-Kun, Chonbuk 565-701, Korea; ${ }^{2}$ Department of Biological Sciences, Chonbuk National University, Chonju 560-756, Korea. - Developmental changes of rays in Korean trees. - (Poster)

The developmental changes and origins of primary and secondary rays were studied in Robinia pseudoacacia, Albizzia julibrissin, Diospyros kaki and Firmiana simplex (storied), and Castanea crenata, Alnus hirsuta and Populus euramericana (nonstoried). Primary rays were very high and composed of large, vertically elongated cells. They were the products of repeated divisions of short cells in the procambium. The first secondary rays arose in the fascicular region at a distance of $500-1000 \mu \mathrm{m}$ from the pith and originated by lateral or terminal splitting off from or segmentation of fusiform initials. In Robinia pseudoacacia ray height increased in the latewood of the first growth ring, and then remained constant after gradually decreasing in the second growth ring, while in the remaining species ray height remained constant through the secondary growth after a marked decrease in the first growth ring. Ray width gradually increased in all samples except Alnus hirsuta and Populus euramericana, which remained constant. While the number of rays per unit area decreased in Robinia pseudoacacia, Albizzia julibrissin, Firmiana simplex and Castanea crenata, it was constant in Diospyros kaki, Alnus hirsuta and Populus euramericana. The proportional volume of rays gradually increased in all species except Castanea crenata where it was constant throughout the secondary growth. 
T. HaTA, L.P. Novicio \& Y. Imamura: Wood Research Institute, Kyoto University, Uji Kyoto 611-0011, Japan. - Ultrastructural change of wood under thermal conversion. - (Poster)

Sugi (Cryptomeria japonica D. Don) was heated by increasing the temperature at $4-50{ }^{\circ} \mathrm{C} / \mathrm{min}$ up to $1300^{\circ} \mathrm{C}$. Morphological change in cross section and microstructure during carbonization were examined by environmental scanning electron microscopy. Charcoal carbonized at $600^{\circ} \mathrm{C}$ and showed a little shrinkage by elevating ambient temperature from room temperature till $1300^{\circ} \mathrm{C}$. On the other hand, the original wood showed drastic changes in the cell shapes over $450^{\circ} \mathrm{C}$ during carbonization.

The wood was carbonized at $700^{\circ} \mathrm{C}$ and then sintered at about $2500^{\circ} \mathrm{C}$. The TEM observations revealed that the microstructure of wood carbonized at $700^{\circ} \mathrm{C}$ showed onion-like hollow graphitic structures. After being sintered at $2500^{\circ} \mathrm{C}$, the graphitic structure of the sintered specimen was analyzed. The plane distance of this graphitic structure is $3.41 \AA$, close to the $3.354 \AA$ of graphite.

Futoshi Ishiguri ${ }^{1}$, Kikuko Saitoh ${ }^{1}$, Minoru Andoh ${ }^{1}$, Zensaku Abe ${ }^{2}$, Shinso Үокота ${ }^{1} \&$ Nobuo Yoshizawa ${ }^{1}:{ }^{1}$ Department of Forestry, ${ }^{2}$ Department of Bioproductive Science, Faculty of Agriculture, Utsunomiya University, Utsunomiya 321-8505, Japan. - Color changes from black to red of black heartwood sugi (Cryptomeria japonica) by smoke-heating and UV irradiation. - (Poster)

In order to investigate the changes of heartwood color by smoke-heat treatment, black-colored heartwood sugi (Cryptomeria japonica D. Don) logs with bark were smoked, heated and smoke-heated separately. In heat and smoke-heat treatments, logs were heated for about 30 hours at a temperature inside the log of over $80^{\circ} \mathrm{C}$. In the treatment of only smoking, logs were smoked for about 30 hours at a temperature inside the $\log$ of $40^{\circ} \mathrm{C}$. After each treatment, changes of heartwood color, amounts of extracts (hot water, $1 \%$ sodiumhydride, ethanol-toluene) and alkali metal ions (sodium, potassium, calcium and magnesium), $\mathrm{pH}$, and changes of heartwood color by UV ( $254 \mathrm{~nm}$ and $365 \mathrm{~nm}$ ) irradiation were examined.

Heartwood color in black-colored sugi changed from black to yellow-white by thermal treatments. However, smoking did not largely change heartwood color. In black heartwood, brightness and yellowness were increased by thermal treatments, whereas redness was decreased. On the other hand, brightness, redness, and yellowness were decreased by smoking. $\Delta \mathrm{E}$ values, indicating the degree of changes in wood color and obtained after each treatment were 7.3, 18.3, 28.8 for smoke, heat, and smoke-heat treatments, respectively. No differences in the amounts of extracts and metal ions were found between control and treated woods. Thermal and smoke treatments decreased $\mathrm{pH}$ from 8.0 to 6.0 and 7.1 , respectively. The results obtained here suggested that color changes in black-colored heartwood of sugi were mainly caused by changes of $\mathrm{pH}$ by both thermal and smoke treatments.

When heartwood specimens were irradiated with UV after each treatment, UV irradiation at $365 \mathrm{~nm}$ gave better effects on heartwood color changes than did irradiation at $254 \mathrm{~nm}$. In the heated and smoke-heated woods, redness and yellowness increased 
by UV irradiation at $365 \mathrm{~nm}$, whereas brightness decreased. As a result, the color of black heartwood of sugi changed from yellow-white to red by UV irradiation; red is the normal heartwood color of sugi wood. However, UV irradiation did not give great changes in the heartwood color in control and smoked wood. These results suggest that UV irradiation to the thermal treated wood increased the redness, as found in redcolored heartwood, which seemed to be caused by some chemical changes of pigments under a weak acidic condition in the black-colored heartwood of sugi.

Tetsuo Itabashi, Nobuo Yoshizawa \& Toshinaga Idea: Department of Forest Science, Faculty of Agriculture, Utsunomiya University, Utsunomiya 321-8505, Japan. - The seasonal occurrence and histological features of septate wood fibers in some Japanese hardwoods. - (Poster)

The seasonal occurrence of septate wood fibers and their distribution within an annual ring were investigated in ring-porous Kalopanax pictus Nakai, and diffuseporous Deutzia crenata Sieb. et Zucc. and Aucuba japonica Thunb. Seasonal observation of a current annual ring showed that the formation of septa in wood fibers starts at the initial part in the current annual ring and progresses towards the cambium. Wood fibers just forming septa were observed only in the current annual ring, indicating that the formation of septa in wood fibers is almost completed in one growing season. In $K$. pictus, septate wood fibers occurred predominantly at the terminal region in an annual ring. These septa were formed after the completion of lignification of wood fiber walls. This is also true in D. crenata and A. japonica.

Observation of the histological features in nine species possessing septate wood fibers in Japanese hardwoods showed that most species have a small amount of axial parenchyma, and that septate wood fibers always contain much starch instead of the axial parenchyma. These results suggest that septate wood fibers have a parenchymalike function. Of the nine species, six species (Meliosma myriantha Sieb. et Zucc., Alalia elata Seem., Acanthopanax sciodophylloides Fr. et Sav., Evodiopanax innovans Nakai, Kalopanax pictus, Pieris japonica D. Don) formed septa perpendicular to the cell wall, whereas three species (Deutzia crenata, Dendropanax trifidus Makino, Aucuba japonica) formed oblique septa. Although helical thickenings were not observed in all the septate wood fibers, they were observed in wood fibers with no septa in some species (Deutzia crenata, Acanthopanax sciodophylloides, Aucuba japonica).

TAKao IтоH \& TAKeshi FujINo: Wood Research Institute, Kyoto University, Uji, Kyoto 611-0011, Japan. - Structural changes of the cell wall during lignification of xylem cells in Eucalyptus tereticornis, visualized by rapid-freezing and deepetching electron microscopy. - (Paper)

The cell wall in living tissue of woody plants should be in a highly hydrated state. For example, the primary wall of differentiating xylem cells is in a swollen condition. The most characteristic change of the cell wall in woody plants is the lignification process which accelerates the transition from the hydrated to the less-hydrated state. The aim of the present investigation is to visualize hydrated and less-hydrated walls as closely as possible to the native state. 
The three-dimensional architecture of the cell wall during lignification in Eucalyptus tereticornis was visualized by rapid-freezing and deep-etching electron microscopy. A highly porous structure was demonstrated in the cell corner, middle lamella and primary walls of both cambium and enlarging xylem cells, but the porosity disappeared after lignification of the xylem cells. The porosity abruptly diminished by the encrustation of lignin as well as by dense deposition of cellulose microfibrils in differentiating xylem cells. This study is the first to detect rosettes, cellulose synthesizing enzyme complexes, in the differentiating xylem cells of a woody plant, and provides the first account of the visualization of the three-dimensional architecture of secondary xylem cell walls before and after lignification.

RISTO JALKANEN: Finnish Forest Research Institute, Rovaniemi Research Station, Pl 16, FIN 96301 Rovaniemi, Finland. - Needle traces - less known structures of conifer stems as environmental indicators. - (Paper)

There are only a few examples except tree rings, in which characters or properties of wood structure have been used in describing environmental changes. Excluding traditional dendrochronology, even rarer are methods or techniques which are able to produce retrospective data about life-time changes in trees. One of these methods is the recently developed Needle Trace Method (NTM). It uses needle traces of conifers, embedded in the innermost tree rings, from the pith outwards. Based on determination of their length with respect of tree rings, needle age of an individual short shoot, i.e. a needle fascicle, is estimated. By extending this procedure to the whole stem length, long-term chronologies for various needle parameters are produced. Among these are retention, age, shedding, production and density of needles, which all indicate changes in the crown, e.g. crown transparency. NTM is applied in living trees as well as in a 4000-year-old Pinus sylvestris stem. NTM is used in a row of conifers. This is shown in a normal, 'healthy' stand, in a stand affected by a needle pathogen and in a polluted environment of $P$. sylvestris.

LaJimina Joshi : Department of Plant Resources, Plant Research Division, Godawari, Nepal. - Ecological wood anatomy of Alnus nepalensis (Betulaceae) in Central Nepal. - (Paper)

Wood anatomical characters of Alnus nepalensis growing in Central Nepal are evaluated against three non-anatomical factors: tree height, diameter at breast height (dbh) and altitude. Samples were taken from the outermost parts of the trunk of dominant trees at seven localities between 600 and $1650 \mathrm{~m}$ above sea level. Tree height ranged from 11 to $20 \mathrm{~m}$ and dbh ranged from 10 to $75 \mathrm{~cm}$. Altitude and tree height are correlated with all the vessel characters studied.

Among wood anatomical characters, vessel characters measured from cross sections are strongly correlated with one another, and also with vessel element and fiber tracheid length. Multiple regression analysis using non-anatomical factors as independent variables resulted in significant correlation at $1 \%$ level in vessel element length and at 5\% level in pore density, tangential vessel diameter, intervessel pit diameter, uniseriate ray height, and bar number of the perforation plates.

Regression coefficients of significant regressions are usually largest for altitude, secondarily for height and dbh. For wood structure of Alnus nepalensis in Central Nepal $22-28 \%$ of the variation can be predicted by non-anatomical factors. 
S. Kaliamooethy ${ }^{1} \&$ K.V. KRIShnamurthy ${ }^{2}$ : ${ }^{1}$ Department of Biotechnology, J.J. College of Arts and Science, Namanasamudhram Post, Pudukkotai - 622 404, Tamil $\mathrm{Nadu}$, India; ${ }^{2}$ Department of Plant Science, Bharathidasan University, Tiruchirappalli 620024 , Tamil Nadu, India. - Influence of plant growth regulators on the control of vascular element differentiation in vitro. - (Paper)

The consensus reached so far is that auxins promote both xylogenesis and phloem differentiation, and that the number of elements differentiated is a function of the concentration of the auxin. Our studies on callus cultures of Cucumis sativus, used as a model system, also broadly agree with these two generalizations stated above. However, our results were contradictory to Aloni's (1980) findings that low concentrations $\left(0.1 \mathrm{mgl}^{-1}\right)$ of auxin promote only phloem and not xylem. In Cucumis sativus callus the same low concentration of auxin used by Aloni favored the differentiation of both phloem and xylem elements in significant quantity. The type of xylem elements formed in calli on xylogenic media were perforate, imperforate or fibers. Possible, a judicial combination of these growth regulators determines the relative proportions of these elements in the callus tissues of any plant.

Terutaka Katoh \& Minoru Kasuya: Department of Public Health, Faculty of Medicine, Toyama Medical and Pharmaceutical University, 2630 Sugitani, 930-0194 Toyama, Japan. - Dendrochronological study of Zelkova serrata in Toyama Prefecture, Japan: a preliminary study using the finger-print method. - (Poster)

A pilot study was carried out to clarify the potential of Zelkova serrata (Thunb.) Makino for future development of dendrochronology in Japan. Zelkova serrata occurs in the Japan Islands and the Korean Peninsula. This tree species is well known as one of the most long-living large trees in Japan. The timber of Zelkova serrata is in Japan quite popular for large wooden buildings such as temples and shrines, and is also one of the most common trees for furniture, woodwork, artwork, etc.

Disk or core specimens were collected from living and newly felled trees of Zelkova serrata growing in the Toyama Prefecture, Central Japan. Ring width of these specimens was directly measured by a digital reading microscope. Ring width series were also determined in Zelkova serrata wood from building materials of shrines and temples, built in the late 18th to the mid 20th century in the Toyama Prefecture. Because no timber specimens of modern or historical buildings were allowed to be taken for analysis, ring-width measurement was carried out using the finger-print method developed by the author. Tree-ring images of weathered transverse surfaces of building material were transferred to a transparent adhesive tape and mounted to a transparent film. Ring width was measured from the transparent tape in the laboratory, using a digital reading microscope. The present study indicates that it is feasible to build a master chronology for Zelkova serrata growing in Japan.

Yoshio KiJidani \& Ryushi KitahaRa: Forest Resources Division, Faculty of Agriculture, Miyazaki University, 1-1, Gakuen Kibanadai Nishi, Miyazaki 889-2192, Japan. - Effect of gibberellic acid on latewood formation in conifers. - (Poster)

The effect of plant hormones on latewood formation was examined in 15-25-yearold plantation trees of Cryptomeria japonica D. Don and Larix leptolepsis Gordon. 
Indole-3-acetic acid (IAA), gibberellic acid $\left(\mathrm{GA}_{3}\right)$ and combinations of IAA and $\mathrm{GA}_{3}$ were dissolved in ethanol and mixed with lanolin. These lanolin pastes were applied to the trunk at breast height during latewood formation.

After treatment, xylem formation at the application sites appeared to be promoted. The applied IAA and hormonal combinations produced rounded latewood tracheids with many intercellular spaces. The rounded tracheids were similar to compression wood tracheids. On the other hand, $\mathrm{GA}_{3}$ alone produced much latewood increment. Therefore, $\mathrm{GA}_{3}$ could be used to promote latewood formation in trees.

Mino Kikuchi ${ }^{1}$, Kiyotsugu Yoda ${ }^{1}$, Mitsuo SuzukI ${ }^{2}$ \& Hrtoshi SuZuki ${ }^{1}:{ }^{1}$ School of Science and Engineering, Ishinomaki Senshu University, Ishinomaki 986-8580, Japan; ${ }^{2}$ Botanical Garden, Faculty of Science, Tohoku University, Sendai 986-0862, Japan. - Fine structures of vessels in Zelkova serrata observed by resin casting method. - (Paper)

That the trunk of Zelkova serrata (Thunb.) Makino can swell and/or shrink in a minute in addition to the well known diurnal fluctuation in stem diameter had not been expected (Yoda et al. 1996). It is plausible that this unexpected behavior should reflect or result from internal morphological changes in the trunk. Since the amplitudes of rapid changes are nearly of the same order as the diameters of vessels, we focused our attention on the morphology of live vessels. We applied the resin casting method (Fujii 1993) to visualize and to separate vessel components.

Freshly isolated stem and/or branch portions were used (without fixation or dehydration) to establish successful polymerization of the resin. The fine structures of these resin-casts were observed by using a scanning electron microscope. Three kinds of resin-casts of vessels were recognized: vessels with both pits and perforation plates, those with only perforation plates and those with only spiral thickening. In addition, the resin-casts of fibrous elements, including those with forked ends and conical ones, were observed.

To examine the functional network of vessels as conducting routes, color ink was sucked from the tip of a stem (diameter $5 \mathrm{~mm}$, length $10 \mathrm{~cm}$ ) basipetally. The ink reached not only to the basal end of the stem but also to the midrib of leaves on lateral branches through their petioles and the vessels in the lateral branches.

Chul-Hwan KIM ${ }^{1}$, Jong-Moon Park ${ }^{2}$ \& Seo-Hwan KIM ${ }^{2}$ : ${ }^{1}$ The National Instrumentation Center for Environmental Management, College of Agriculture \& Life Sciences, Seoul National University, Korea; ${ }^{2}$ Department of Forest Products, Chungbuk National University, Cheongju 361-763, Korea. - Effect of fiber wall thickness on paper properties using confocal laser scanning microscopy. - (Paper)

Refining in papermaking plays an important role in changing fiber properties as well as paper properties. The major effects of refining on pulp fibers are internal and external fibrillation, fiber shortening and fines formation. Many workers have shown that internal fibrillation was most significant in improving fiber and paper properties. In particular, refining produces breakdown of fiber walls into separate lamellae, thus causing fiber wall swelling with water penetration. This leads to an increase of fiber flexibility and of fiber-to-fiber contact area. In order to study the effect of fiber wall 
delamination on fiber and paper properties, cross-sectional images of fibers in a natural condition had to be generated by optical sections without distortion. Confocal laser scanning microscopy (CLSM) is one of the most efficient tools for quantifying fiber wall delamination in combination with image analysis. In this study, the CLSM could be used not only to observe morphological features of transverse views of swollen fibers refined under low and high intensity, but also to investigate the sequence of fiber wall delamination and fiber wall breakage. Furthermore, through a positive correlation of fiber wall delamination with fiber and paper properties, it was confirmed that fiber wall delamination could be used as an excellent measure to predict fiber and paper properties before and after refining.

Dae-Young Kim, Masahisa Wada, Shigenori Kuga \& Takeshi OKano: Department of Biomaterials Science, Graduate School of Agricultural and Life Sciences, The University of Tokyo, Bunkyo-ku, Tokyo 113-8657, Japan. - Wood pyrolysis investigated by X-ray diffraction and SEM. - (Paper)

Wood pyrolysis was investigated using a highly oriented crystalline sample, tension wood of Populus maximowiczii, by X-ray diffraction and SEM. The sample was heated in air from room temperature to $360^{\circ} \mathrm{C}$ at a rate of $5^{\circ} / \mathrm{min}$., and X-ray diffraction was recorded at a given temperature by PSPC (position sensitive proportional counter). Three major equatorial reflections were observed in the profile. These peaks were shifted to a lower angle region with increasing temperature. On the other hand, integral intensity of diffraction including crystal reflections decreased with increasing temperature, and almost disappeared at $360^{\circ} \mathrm{C}$. These changes of profiles were ascribable to thermal expansion, thermal vibration and pyrolysis of wood cellulose.

In order to extract the information concerning wood pyrolysis, we recorded X-ray diffraction profiles every $10 \mathrm{~min}$. up to $90 \mathrm{~min}$. at the holding temperature of $320^{\circ} \mathrm{C}$. Integral intensity of crystalline reflections decreased and full-width at half maximum (FWHM) of those reflections increased with duration time, respectively. By analyzing changes of those integral intensity and FWHM precisely, we followed changes in crystallite size and crystallinity of cellulose during pyrolysis. The ultrastructure of the pyrolyzed sample was observed by SEM and will be presented.

Nam-Hun Kim, Chungjoon Lee \& Wonjoog Hwang: Department of Wood Science \& Technology, College of Forest Sciences, Kangwon National University, Chunchon 200-701, Korea. - Anatomical and physical properties of Pinus koraiensis damaged by forest fire. - (Paper)

Anatomical characteristics such as tracheid length, tracheid number across a growth ring, ray number, ray height and number of resin canals in a trunk of Pinus koraiensis wood damaged by a forest fire were studied by light microscopy combined with an image analyzing system. Ring width, green moisture content and basic density were also examined. The properties of damaged and undamaged areas in a disc were compared.

Tracheid length of the damaged area was $3.21 \mathrm{~mm}$, and that of undamaged earlywood and latewood was $4.46 \mathrm{~mm}$ and $4.65 \mathrm{~mm}$, respectively. The number of tracheids across a growth ring was 20.3 in the damaged area and 61.5 in an undamaged area. 
The number of rays per $\mathrm{mm}^{2}$ in tangential section was 10.6 in the damaged area and 12.0 in undamaged areas. Ray height in number of cells was 5.8 in the damaged area and 7.2 in the undamaged area. Radial resin canals existed in both areas and the number per $\mathrm{mm}^{2}$ was highest in the damaged area: 1.0 in the damaged and 0.7 in the undamaged area. The number of longitudinal resin canals along the tangential direction was 1.0 per $\mathrm{mm}$ and solitarily distributed in both areas. The average ring width in damaged and undamaged areas was $0.82 \mathrm{~mm}$ and $2.80 \mathrm{~mm}$, respectively. Green moisture content of the damaged area (125\%) was lower than that of the undamaged area $(280 \%)$. Basic density (dry mass/green volume) showed a significant difference between damaged and undamaged area: $0.58 \mathrm{~g} / \mathrm{cm}^{3}$ and $0.37 \mathrm{~g} / \mathrm{cm}^{3}$, respectively.

NAM-Hun Kim ${ }^{1}$, R. VuOng ${ }^{2} \&$ H. ChanzY ${ }^{2}:{ }^{1}$ Department of Wood Science and Technology, College of Forest Sciences, Kangwon National University, Chunchon 200701, Korea; ${ }^{2}$ Centre de Recherches sur les Macromolecules Végétales-CNRS, BP 53, 38041 Grenoble Cedex 9, France. - The structure of cellulose microfibrils in mistletoe berries. - (Poster)

The structure and morphology of the cellulose microfibrils in mistletoe (Viscum album L.) berries were examined with optical microscopy and transmission and scanning electron microscopy. Fresh mistletoe berries were slit open and observed by scanning electron microscopy after critical point drying. Some strands/filaments were found in a mucilaginous substance called viscin. Viscin cells can be stretched to form very long strands up to $10-20 \mathrm{~cm}$. The filaments were about 2 to $3 \mu \mathrm{m}$ in diameter and clearly visible by optical microscopy in Nomarski contrast or in polarized light. These filaments were examined by transmission electron microscopy, before and after disencrustation with $\mathrm{NaOH} 4 \%$ (w/v) and Updegraff reagent. In these micrographs, the microfibrillar nature of the filaments could be clearly revealed after shadowing or negative staining. Each filament consisted of an assembly of more or less stretched, endless cellulose microfibrils with a diameter of c. $3 \mathrm{~nm}$. From electron diffraction analysis, one of the disencrusted filaments showed clearly an oriented fiber electron diffraction diagram of the cellulose I. This diagram indicated also that the crystallinity of cellulose in mistletoe was comparable to that of wood, i.e. somewhat higher than that of parenchymal cellulose but lower than that of cotton or ramie cellulose.

Soo-Choul Kim, Min-Jeong Ku, Jae-Beom Jeon, Yung-Jo Lee \& Won-Kyu Park: Department of Forest Products, College of Agriculture, Chungbuk National University, Cheongju 361-763, Korea. - Species and microscopic examination of peat woods excavated from Pyungtaek in Korea. - (Poster)

The objective of this study was to examine both species and the degree of decay of the peat woods (c. 5700 BP) excavated at Higokri, Pyungtaek in Korea. Growth rings of 8 large logs (diameter $>15 \mathrm{~cm}$ ) were also analyzed to determine the age class and to obtain a chronology. Major species were Alnus sp. (38.1\%) and Fraxinus sp. (23.8\%), followed by Quercus sp. (Lepidobalanus; 14.3\%), Juglans mandshurica (11.9\%), Ulmus sp. (4.8\%), Rhamnus davurica (4.8\%) and Prunus sp. (2.4\%). The species composition indicated that the sample region was a swamp or lakeside, which appeared to be formed due to the sea-level rise after the last glacial era. 
The logs consisted of 5 Alnus and 3 Fraxinus trees. The estimated ages of Alnus and Fraxinus were 56-75 and 34-104 years, respectively. The ring-width patterns suggest that most Alnus trees died simultaneously. From Alnus logs a 120-year-long tree-ring chronology was made. The results of microscopic examination indicated that cell walls were attacked mainly by bacteria. The cells retained their original forms, but their secondary walls were mostly decomposed.

Yoon Soo KIM ${ }^{1}$, AdYA SINGH ${ }^{2}$ \& IK Joo KIM ${ }^{3}$ : ${ }^{1}$ Department of Forest Products and Technology, Chonnam National University, Kwangju, Korea; ${ }^{2}$ New Zealand Forest Research Institute Ltd., Private Bag 3020, Rotorua, New Zealand; ${ }^{3}$ National Maritime Museum of Korea, Mokpo, Korea. - Ultrastructural characteristics of archeological compression wood degradation in waterlogged conditions. - (Paper)

Wood samples submerged for 2200 years in the mud of a rice field at Mooahn-Gun in South Korea were excavated and processed for observation with a transmission electron microscope (TEM). Degradation of pine compression wood occurred mainly in the inner part of the $S_{2}$ layer. In contrast, the outer part of the $S_{2}$ layer remained relatively intact. TEM showed the erosion type of bacterial attack to be dominant in the secondary cell walls of both severe and mild compression wood. However, other forms of microbial attack such as bacterial tunneling were also present. Bacterial attack in the severe compression wood was mainly confined to the inner part of the $S_{2}$ layer whereas in the mild compression wood it also extended into the outer part of the $S_{2}$ and the $S_{1}$ layer. The extent of degradation correlated the differences in amount and distribution of lignin, particularly in the outer $S_{2}$ layer between the severe and mild compression wood tracheids.

MARIKo KIYOSHIGE ${ }^{1}$, MoRITOSHI IINO ${ }^{2}$ \& TAKAO ITOH ${ }^{1}$ : ${ }^{1}$ Wood Research Institute, Kyoto University, Uji 661-0011, Japan; ${ }^{2}$ Botanical Gardens, Faculty of Science, Osaka City University, Kisaichi, Katano-shi, Osaka 576-0004, Japan. - The effect of auxin on the polarity of tracheid arrangement in Pinus thunbergii. - (Poster)

The aim of the present investigations is to know the major agent that controls the polarity of xylem cells. It is known that the arrangement of fusiform initial cells gradually change from longitudinal to transverse after specific girdling of the bark. The girdling was done at $10 \mathrm{~cm}$ above the ground in 130 stems of 4-year-old Pinus thunbergii trees on April 23, 1997. Three wood blocks $(3 \times 5 \times 6 \mathrm{~mm})$ were cut with a saw to collect transverse parts of bridges every week, until August 27. For auxintransport studies the wood blocks were placed between $1.2 \%$ agar blocks $(6 \times 6 \times 3$ $\mathrm{mm}$ ), which were kept in vertical position and in contact with the newly cut surface. The donor blocks were always on top and the receiver on the bottom. The donor blocks were loaded with $(5-3 \mathrm{H})$ Indole-3-acetic acid. The radioactivity of receiver blocks was counted in scintillation solution. After the termination of the individual auxin-transport experiments, transverse and tangential sections were cut from wood blocks by a microtome, followed by light microscopic observation of the change of tracheid arrangement.

After the initiation of girdling, an increase in radioactivity which suggests the actual flow of auxin from right to left was first observed on the 56th day. Then, the radioactivity gradually increased. On the 70 th day after girdling, the level of radioac- 
tivity was the same or higher than control radioactivity which was counted as longitudinal flow of auxin in intact trees. This result shows that the transverse auxin polar transport was established at the 70th day on transverse bridges. The change of the arrangement of fusiform initials was estimated from measuring their transverse cell length observed in transverse sections. The length gradually increased from the 56th to the 84th day, and abruptly increased from the 84th to the 126th day. The evidence suggests that the establishment of transverse auxin transport preceeds the change of cambial initial arrangement to the transverse direction. It is presumed that the directional flow of auxin may be involved in the arrangement of tracheids.

S. KOGA ${ }^{1}$, T. FUJImoto ${ }^{2} \&$ K. ODA ${ }^{3}:{ }^{1}$ Research Institute of Kyushu University Forests, Faculty of Agriculture, Kyushu University, Fukuoka 811-2415, Japan; ${ }^{2}$ Hokkaido Forest Products Research Institute, Hokkaido 071-0198, Japan; ${ }^{3}$ Department of Forest Products, Faculty of Agriculture, Kyushu University, Fukuoka 812-8581, Japan.

- Effect of thinning on wood formation of Larix kaempferi. - (Poster)

Previously we have reported that thinning affects ring width, radial diameter, wall thickness of tracheids and tracheid length, but does not significantly affect latewood percentage, cell wall percentage of individual growth rings and basic density in Larix kaempferi. In this study, the seasonal wood formation at breast height in Larix kaempferi trees from a thinned plot and an unthinned (control) plot was examined.

Trees from the thinned plot showed a significant increase in ring width, earlywood width and latewood width after treatment compared to trees from the control plot. The division of the cambial cells in trees from a thinned plot tended to initiate a little earlier than in trees from the control plot. The initiation date of latewood tracheid production was not influenced by thinning. The division of the cambial cells in trees from a thinned plot tended to cease a little later than in trees from the control plot. Trees from the thinned plot produced more tracheids than trees from the control plot in the late part of the growing season, although there was no significant difference in the rate of tracheid production in the early part of the growing season.

K. Kuroda ${ }^{1}$, H. Kuroda ${ }^{2}$ \& A.M. Lewis ${ }^{3}:{ }^{1}$ Hokkaido Research Center, Forestry and Forest Products Research Institute, Hitsujigaoka-7, Toyohira-ku, Sapporo 0628516, Japan; ${ }^{2}$ Wood Research Institute, Kyoto University, Uji, Kyoto 612-0011, Japan; ${ }^{3}$ Department of Forestry and Wildlife Management, University of Massachusetts, Amherst, MA 01003-4210, USA. - Detection of embolism and acoustic emissions in tracheids under a microscope: incidence of diseased trees infected with pine wilt. - (Poster)

Xylem sap in water conduits is kept under tension when transpiration is active. The conduit's water columns can break under high tension and form bubbles (emboli). In healthy plants, water columns recover by rehydration when the tension is reduced. In trees infected with wilting diseases, however, sap ascent finally stops without recovering in dehydrated xylem areas. We observed embolism in light-microscope sections of diseased trees and confirmed the relationship between bubble development and acoustic emissions (AEs) that are detected at embolism. We discuss the mechanism of water blockage in pine wilt disease. 
Three-year-old Japanese red-pines (Pinus densiflora), inoculated with pine wood nematodes (Bursaphelenchus xylophilus) and healthy trees, were used. Embolism was observed in radial sections $(1 \times 6 \mathrm{~mm})$ of $60 \mu \mathrm{m}$ thick that contain a layer of intact tracheids, and was recorded on videotape (Lewis' method). At the same time, AEs were monitored with an AE-transducer attached to the sections. As the second experiment, the time necessary for the rehydration of healthy and infected pines following the addition of water was compared.

First, dehydration without AEs occurred from cut-ends of tracheids injured during sectioning. Then, bubbles emerged near the centers of intact tracheids, abruptly expanded, and filled whole tracheids. Such bubble expansion is thought to occur by the evaporation of water into a very tiny bubble. During high-rate bubble formation, AEs were produced. We successfully recorded AEs as audible-sound through the audio terminal of the VTR. The AEs coincided with almost all of the rapid bubble development. This result supports the idea that AEs detected in the trunks of living trees are produced by embolisms in tracheids. Two weeks after inoculation of the pathogen, water blockage by embolism had just occurred in a part of the xylem. In such trees, the time necessary for rehydration is longer than in healthy trees. This suggests that certain substances that inhibit bubble dissolution may exist in xylem.

Hyoung Woo Lee, Yoon Soo Kim \& Won Tek So: Department of Forest Products \& Technology, Chonnam National University, Kwangju 500-757, Korea. - Anatomical characteristics of laser-cut wood surfaces. - (Poster)

The use of a laser for cutting wood offers a number of advantages over conventional machining processes. However, carbonized charred surface and lack of parallelity of kerf limit the application of laser-cutting to machining. The purpose of this study was to investigate characteristics of laser-cut wood surfaces and the relationships between cut-surface quality and wood anatomical characteristics. An air-jet-assisted carbon-dioxide laser rated at a total power of 2.0 kilowatts was used to cut $2.0 \mathrm{~cm}$ thick samples of red oak (Quercus rubra) and hard maple (Acer saccharum). Samples were prepared to have four different angles between grain and cutting direction, 0 , 30,45 , and 90 degrees. Brightness and roughness of cut-surfaces were measured by image analysis and with a non-contact laser displacement sensor. The surface characteristics were examined also by light and scanning electron microscopy (SEM). Experimental results show that maximum feed speed at the point of full penetration of the laser beam decreased with increasing the angle between grain and cutting direction. Center line average roughness of laser-cut surfaces was higher than that of sawn surfaces. The highest grey level of laser-cut surfaces was obtained when red oak was laser-cut parallel to the grain. Waviness of the cut surface was generally apparent in a ring-porous wood such as red oak where density variations throughout the wood structure are pronounced. In contrast, hard maple showed a relatively smooth cut surface. Higher roughness of laser-cut surfaces is presumably mainly due to wood rays, which have been melted to a greater depth than neighboring cells. High-temperature smoke 
produced during laser cutting of wood was exhausted mainly through vessels and charred deeply into vessel walls. The present study suggests that anatomical characteristics of wood species play an important role in determining the quality of laser-cut surfaces.

Kyu Bae LeE ${ }^{1}$ \& Woong Young SoH ${ }^{2}$ : ${ }^{1}$ Department of Biological Science Education, Chosun University, Kwangju 501-759, Korea; ${ }^{2}$ Department of Biological Sciences, Chonbuk National University, Chonju 560-756, Korea. - Vascular cambium in rhizomes of Botrychium ternatum: anatomy, ultrastructure and histochemistry. - (Paper)

The vascular cambium of Botrychium ternatum rhizome was studied at anatomical and ultrastructural levels. Cambium at the 6th internode (6-year-old cambium) had the greatest number of active cambial cells in August and September, thus it was in the most active stage. The active cells were characterized by the presence of a large vacuole, few storage materials such as starch grains within plastids and lipid droplets, a thin tangential wall, and various cell organelles in the thin layer of peripheral cytoplasm. When the 6-year-old cambium reached its dormant season after November, the cambial cells were filled with numerous storage materials and contained few cell organelles. The activity of acid phosphatase in 6-year-old cambium was strong in September but weak in August and October. The initiation and cessation of cambial activity might be correlated with the annual life cycle of this plant: the vegetative and reproductive leaves began to emerge in June and July, respectively, and the sporophyll withered in November after spore dispersal. Most cambial cells at the 10th internode, which remained dormant throughout the year, were filled with abundant storage materials. Our results indicate that with age the meristematic activity of the cambial cells was markedly reduced or had ceased. Therefore, the rhizome of Botrychium ternatum has a determinate vascular cambium which might be much less specialized than that of woody plants.

PhIL Woo LeE: Department of Forest Products, Seoul National University, Suwon, Korea. - Wood anatomical characteristics and identification of indigenous and imported pine trees grown in Korea. - (Poster)

The possibility of wood identification of eight pine species grown in Korea was studied. In general features, the woods of soft pines (Korean, Parviflora and Eastern White pine) have a gradual to slightly abrupt transition of early- to latewood and have comparatively narrow sapwood. In contrast the woods of hard pines (Korean Red, Korean Black, Jack, Pitch and Loblolly pine) have an abrupt to very abrupt early/ latewood transition and wide sapwood.

Microscopically, in ray tracheid dentation and crossfield pitting three groups can be distinguished: 1 2 large window-like pits and dentation present (Korean Red and Korean Black pine), 1 6 pinoid pitting and dentation present (Jack, Pitch and Loblolly pine); and 1 2 large window-like pits per crossfield and dentation absent (Korean, Parviflora and Eastern White pine). 
PHIL Woo LEE: Department of Forest Products, Seoul National University, Suwon, Korea. - Wood anatomical characteristics of coniferous and broad-leaved tree genera of Korea. - (Poster)

This study was carried out to investigate the wood anatomical characteristics of softwoods and hardwoods including exotics grown in Korea.

The wood specimens of the Wood Anatomy Laboratory, College of Agriculture and Life Sciences, Seoul National University, and macerated wood fibers and permanent slides were utilized as study material: 61 specimens, 31 species and 16 genera of conifers and 514 specimens, 286 species and 153 genera of hardwoods collected from all over the country.

Macroscopical features as, for instance, annual rings, sap and heartwood, wood rays, wood color, odor and taste were observed. Microscopical features such as vessels, tracheids, wood fibers, longitudinal and ray parenchyma, ray composition, and intercellular canals were examined by light microscopy. From the results of the macroscopical and microscopical study of the species, the anatomical characteristics were tabulated by genus.

SUnG-JAE LEE ${ }^{1}$ \& PIETER BAAs ${ }^{2}$ : ${ }^{1}$ Forest Research Institute, Kangwon Province, 132-2 Woodu-dong, Chunchon 200-150, Korea; ${ }^{2}$ Rijksherbarium/Hortus Botanicus, P.O. Box 9514, 2300 RA Leiden, The Netherlands. - Wood anatomy of Hamamelidaceae. - (Poster)

The Hamamelidaceae constitute a family of trees and shrubs occurring in subtropical and temperate climates, especially in Eastern Asia and North America. A few taxa occur in North Australia and South Africa. According to the literature, there are 30 genera and about 100 species in this family. This study was carried out to explore microscopic structures that can be used in wood identification and classification. In total 25 genera and 50 species of Hamamelidaceae were obtained from a number of institutional wood collections or specially collected and examined by light and scanning electron microscopy.

The wood anatomy of the Hamamelidaceae show very limited variation and can be characterized as relatively primitive in the Baileyan sense. All of the species are diffuse-porous. The vessels in all species are mostly solitary with but very few radial and tangential multiples. Vessel elements are long and narrow with scalariform perforation plates. In Loropetalum, Altingia and Semiliquidambar helical thickenings are present throughout the vessel elements; in Corylopsis and Liquidambar helical thickenings are restricted to the vessel element tails. Loropetalum has helical thickenings in ground tissue fibers as well. Banded parenchyma is found in six genera. Both the intervessel and vessel-ray pits are mainly scalariform to opposite. Rays are heterogeneous, usually 1-3 cells wide, but in some genera they are exclusively uniseriate. Crystals are present in almost all the species.

The limited wood anatomical diversity within the family does not lend itself well for phylogenetic analysis, but it is possible to key out most genera on a combination of qualitative and quantitative characters. 
Dong OK LIM ${ }^{1}$ \& WoOng Young SoH ${ }^{2}:{ }^{1}$ Department of Biology, Honan University, Kwangju 506-714, Korea; 2 Department of Biology, Chonbuk National University, Chonju 560-756, Korea. - Cambial development and length of tracheary elements and fibers in dwarf trees. - (Poster)

From a comparison of cambial cells and their derivatives between naturally occurring dwarf trees and normal ones, it was concluded that tracheary elements and fibers in the annual rings of dwarf trees are shorter, narrower and fewer than those of normal trees. The frequency of anticlinal division and loss of cambial initials is low during differentiation of xylem cells from cambial initials in dwarf trees. The length and intrusive growth of fusiform initials are slightly less than those of normal trees. These results agree with those in Pinus koraiensis subjected to water stress. Thus, it is concluded that the shortening of tracheary elements and fibers in dwarf trees is due to the fact that cambial initials are themselves shortened and that intrusive growth during differentiation of xylem mother cells did not occur. It is suggested that the variation of xylem element lengths in dwarf trees is related to harsh environmental conditions such as water stress.

Wenda Lu, YiXiang Liu, Yongzhi Cui, Chuanping Yang \& Shuwen Yang: Northeast Forestry University, Harbin 150040, People's Republic of China. - A preliminary study on heterosis and the selection of optimal provenance by the determination of wood properties in plantation-grown Larch. - (Paper)

The analysis of the growth and wood properties of 15-year-old plantation-grown Larch from eight different geographic provenances and four hybrids of JL $\times$ OHL, $\mathrm{DL} \times \mathrm{OHL}, \mathrm{DL} \times \mathrm{JL}$ and $\mathrm{JL} \times \mathrm{DL} *$ showed that: (1) Among the eight geographic provenances, the XiaoBeihu is the optimal one not only in growth but also in the index of wood properties. (2) The growth rate and index of wood properties of four hybrids are superior to the eight geographic provenances. These results on the heterotic vigor of Larch species are similar to those of other investigators. (3) Through the complex evaluation of wood properties, we found that the $\mathrm{JL} \times \mathrm{OHL}$ is the best hybrid species among the four hybrids for engineering and pulp and paper utilization.

*) Legend: JL = Japanese Larch (Larix kaempferi (Lamb.) Carrière); DL = Dahurian Larch (Larix gmelini Rupr.); OHL = Olga Hay Larch (Larix olgensis Henry).

Hiroshi Matsunaga, Junji Matsumura, Kazuyuki Oda \& Motoaki Okuma: Department of Forest Products, Faculty of Agriculture, Kyushu University, Fukuoka 812-8581, Japan. - The liquid flow pathways in Japanese larch (Larix kaempferi) heartwood - The difference between vacuum and pressure treatment. - (Poster)

Japanese larch (Larix kaempferi), a refractory species, was studied. From naturaldried logs, end matched wood samples ( $448 \mathrm{~cm}$ long) were prepared from heartwood; the opposite side was ethanol treated. Liquid (toluidine blue solution) impregnation with vacuum and pressure treatment was investigated.

Liquid flow pathways predominantly depended on the wood anatomy and structure. For example they were greatly affected by the condition of bordered pits and resin canals. The liquid flow pathways of vacuum-treated wood were considered as follows. Compared with natural-dried wood, the penetrated depth in wood extracted 
with ethanol was much longer, especially in the transition area to latewood within the annual rings. Furthermore, the resin canal network in extracted wood acted as liquid flow pathways. However, rays had no function for the liquid penetration in either natural-dried or extracted wood.

Although the liquid flow pathways in pressure-treated wood were the same as those in vacuum-treated wood, it was observed that the dye penetrated from the resin canals into tracheids and rays in extracted wood. In the case of severe pressure-impregnation, the main flow pathways were axial tracheids of both earlywood and latewood. For resin canals no differences were found with vacuum-treated wood. However, dye impregnation of rays occurred only in earlywood of natural-dried wood while it occurred in both earlywood and latewood of extracted wood.

Y. Midorikawa \& M. Fujita: Division of Forest and Biomaterials Science, Graduate School of Agriculture, Kyoto University, Sakyo-ku, Kyoto 606-8502, Japan. Change of tracheid shapes within an annual ring traced by the Fourier transform image analysis. - (Poster)

It is well known that softwood tracheid shape changes from earlywood to latewood. The transition is an important character in softwood identification. The Fourier transform image analysis (FTIA) was introduced here to quantify the transition. Transverse sections of some softwoods were used in the analysis. The dot maps and net maps were extracted from normal annual rings and divided evenly into five tangential bands. As each band is very slender, bands were cut into three parts and then gathered to a field before FFT treatment. The shapes and arrangements of tracheids in each band were characterized by FTIA. Although some tracheids overlapped with one another, the power spectral patterns after the FFT treatment were little affected by the overlapping. This improvement is based on the theory that the phase information can be eliminated on the power spectrum. On the other hand, some shape factors such as radial diameters were measured directly on the enlarged photographs and then traced along radial rows of tracheids. From FTIA the most probable tracheid shape was reconstructed in each band, and compared with one another. The results obtained are as follows: the shapes are hexagonal in every band; the radial diameters become maxi$\mathrm{mal}$ in the $2 \mathrm{nd}$ band and decrease to the terminal band; the tangential diameters are constant except for that of the initial band. Except for the initiation zone of annual rings, tracheid shapes are similar and only affected by the change of radial diameter along tracheid rows. If the typical tracheid shape is evaluated in the earlywood by FTIA and then radial diameters and tangential wall thickness are traced within an annual ring by ordinary measurement, the transition will be characterized.

Noato MikajiRi \& Junji Matsumura: Department of Forest Products, Faculty of Agriculture, Kyushu University, Fukuoka 812-8581, Japan. - The relation between flow pathways and the resin canal system of conifers. - (Poster)

Resin canals are a constant feature of wood of Pinus, Picea, Pseudotsuga and Larix, and show a three-dimensional anastomosis system. To investigate the relation between flow pathways, permeability and resin canal system, ethanol extraction was adopted to remove resins, subsequently air-dried Pinus (two species), Spruce, and Douglas fir heartwood were impregnated by vacuum treatment with water and tolui- 
dine blue. After the weighting a stereoscopic microscope was used to observe the flow pathways of toluidine blue. By means of scanning electron microscopy and image-analysis the condition and sizes of bordered pits, and the distribution and number of axial and radial resin canals were investigated. Uptakes of two Pinus species and Spruce were increased by ethanol extraction; on the other hand Douglas fir remained constant. One Pinus species revealed the largest rate of increase (an average of $\times 2.86$ ). The flow pathways of radial and axial resin canals played an important role for increasing the uptakes in two Pinus species. In spruce, ethanol extraction mainly increased the flux in latewood tracheid and radial resin canals. Douglas fir revealed the largest uptakes $\left(0.554 \mathrm{~g} / \mathrm{cm}^{3}\right)$ and the main flow pathways were revealed in both earlywood and latewood. Therefore, in Douglas fir the resin canal system was not involved in permeability. The one Pinus species which revealed the largest rate of increase had unthickened parenchyma and epithelial cells in both axial and radial resin canals. There was a significant correlation between the rate of uptake increase and sizes and numbers of axial and radial resin canals.

AkiYoshi Mishiro ${ }^{1}$, Rudolf E. BookeR ${ }^{2}$ \& Nick W ARD $^{3}$ : ${ }^{1}$ Faculty of Agriculture, Niigata University, 8050 Ikarashi 2-no-cho, Niigata 950-2102, Japan; ${ }^{2}$ New Zealand Forest Research Institute, Private Bag 3020, Rotorua, New Zealand; ${ }^{3}$ Previously New Zealand Forest Research Institute, Private Bag 3020, Rotorua, New Zealand. Effect of knots on the development of bow and crook in radiata pine boards during drying. - (Paper)

The effect of knots on bow and crook over a distance of $600 \mathrm{~mm}$ was examined for single knots in $2 \times 4$ " (100 by $50 \mathrm{~mm}$ ) radiata pine boards that had been kiln dried without constraint. The position, size and associated grain deviation of all the single knots in each board were carefully recorded on a transparent overlay that surrounded all four planes of the board section that contained the knot. The knot area and the grain deviation around the knot were projected on the board cross section. The centroids of this knot area and of the area of grain distortion around it were obtained and the differences between the coordinates of these centroids and the centroid of the board cross section were defined as offset $\mathrm{Kw}$ and offset $\mathrm{Kt}$ in width and thickness direction respectively for the knot area and $\mathrm{Gw}$ and $\mathrm{Gt}$ for the grain deviation area. Positive and negative sign conventions for bow, crook, offset $\mathrm{Kw}, \mathrm{Kt}, \mathrm{Gw}$ and $\mathrm{Gt}$ are also defined. The overlay technique is capable of identifying for each individual board after sawing the original branch diameter and orientation that gave rise to the knot. It is shown that the possible knot types in a board depend on the annual ring orientation, so that boards that are quartersawn $\left(\theta=0^{\circ}\right)$ cannot have face knots, while flat-sawn boards $\left(\theta=90^{\circ}\right)$ can never have edge knots. The closer a knot lies to one of the surfaces and the greater the original branch diameter, the greater the resulting bow and crook.

T. NAKaI ${ }^{1}$, H. ABE $^{2}$ \& A. KoIzUmi ${ }^{1}$ : ${ }^{1}$ Institute of Wood Technology, Akita Prefectural College of Agriculture, 11-1 Kaieizaka, Noshiro, Akita 016-0876, Japan; ${ }^{2}$ Forestry and Forest Products Research Institute, Tsukuba Norin, P.O. Box 16, Tsukuba 305-8687, Japan. - An estimation of the pressure potential in developing xylem and phloem cells through measurement of tangential strain on the stem surface. - (Poster) 
Tangential strain on the surface of an inner bark was measured using strain gauges in cloned saplings of 3-year-old Cryptomeria japonica and 2-year-old Machilus thunbergii grown in a growth cabinet. Pressure potential (turgor pressure, $P_{\text {cal }}$ ) in developing xylem and phloem cells was calculated using the finite element method (FEM). In the FEM analysis, experimental values for tangential strain and material properties of the inner bark were obtained through tensile tests. A hollow cylinder model, which is a three-dimensional orthotropic body, was adopted as a stem model. Additionally, in order to compare the relation of pressure conditions in the young leaves and the stem, the xylem pressure, $P_{\mathrm{x}}$, of the young leaves were measured with the pressure chamber method.

From the FEM analysis, the average ranges (i.e., magnitude of difference between maximal value and minimal value) of $P_{\text {cal }}$ within a day were estimated $0.65 \mathrm{Mpa}$ (C. japonica) and $0.45 \mathrm{Mpa}(M$. thunbergii). From the pressure chamber method, the absolute ranges of $P_{\mathrm{x}}$ within a day were $0.67 \mathrm{Mpa}(C$. japonica) and $0.39 \mathrm{Mpa}(M$. thunbergii).

Similarity of these ranges showed a close relation between the leaf pressure potential and the stem strain. It is presumed that these results indicate the relation between water conditions in the leaf, branch and stem.

Shuichi Noshiro ${ }^{1} \&$ Pieter BaAs ${ }^{2}$ : ${ }^{1}$ Forestry and Forest Products Research Institute, Tsukuba Norin, P. O. Box 16, Ibaraki 305-8687, Japan; ${ }^{2}$ Rijksherbarium/Hortus Botanicus, P.O. Box 9514, 2300 RA Leiden, The Netherlands. - Ecological wood anatomy of Cornus s.l. (Cornaceae). - (Poster)

Cornus s.l. shows a clear latitudinal trend in several wood anatomical characters. The trends are especially clear in vessel element length and fiber length, for which values at the eaquator nearly halved at $40^{\circ} \mathrm{N}$. Latitudinal trends within several species of Cornus will be compared with those at the genus level, and will be discussed in relation to climatic or geophysical factors and to intra- and interspecific phylogeny. Trends in Cornus will also be compared with those in several other genera showing similar latitudinal trends.

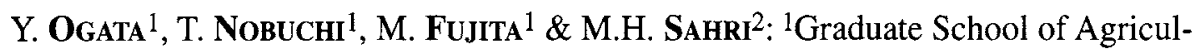
ture, Kyoto University, Kyoto 606-8502, Japan; ${ }^{2}$ Faculty of Forestry, Universiti Putra Malaysia, 43400 UPM Serdang, Selangor, Malaysia. - Growth ring formation in young trees of Hevea brasiliensis and Acacia mangium. - (Paper)

In general, tropical trees, especially trees in tropical rain forests, do not form clear annual rings. However, some of them do have growth rings. Relationships between tree growth (elongation and radial growth) and growth ring formation might be more complex in young trees of the tropical forest. Some fundamental characteristics of growth ring formation in young tropical trees, therefore, have been investigated aiming to understand the relationship between growth ring and annual ring.

In this study 30 young trees of Hevea brasiliensis and Acacia mangium were planted in October 1996 in the suburb of Kuala Lumpur, Malaysia in the tropical rain forest zone. They were used to investigate the time of growth ring formation and the characteristics of growth ring structure. Elongation and radial growth of each tree were also 
measured with a measuring pole and a caliper with digital scale, respectively. The term of the experiment was from June 1997 through September 1998.

In Hevea almost all trees had several growth rings (at most 5 rings as of June 1998). There were three stages of elongation growth in this species, namely (1) shoot elongation, (2) leaf maturation without shoot elongation and (3) no changes in appearance in newly formed shoots. The growth ring boundaries were visible as darker layers on the wood disk and the time of their formation approximately coincided with the third stage mentioned above. Thus, in young rubber trees growth ring boundaries coincide with the pause of shoot elongation and leaf maturation.

Some Acacia trees shed leaves on branches of the lower half of the tree in the period from May to June 1998 and after the shedding they formed new leaves in some of the branches. The relationship between leaf shedding and growth ring formation is under investigation.

Yoji Ohashi ${ }^{1}$, Mohd Hamami Sahri ${ }^{2}$, Nobuo Yoshizawa ${ }^{1} \&$ Takao IToh ${ }^{3}:{ }^{1}$ Department of Forest Science, Faculty of Agriculture, Utsunomiya University, Utsunomiya 321-8505, Japan; ${ }^{2}$ Faculty of Forestry, University Putra Malaysia, Serdang, Selangor, Malaysia; ${ }^{3}$ Wood Research Institute, Kyoto University, Uji, Kyoto 6110011, Japan. - Annual rhythm of xylem growth in rubberwood trees (Hevea brasiliensis) grown in Peninsular Malaysia. - (Poster)

The periodicity of the growth increment of six rubberwood trees (Hevea brasiliensis Muell. Arg.) grown in Peninsular Malaysia was investigated continuously for three years using the pinning and dendrometric methods. Climatic data were analyzed for obtaining the correlation with the seasonal rhythm of radial growth and circumferential increments. Aluminum-band dendrometers were placed at breast height level of six sample trees on January 20, 1993. In the pinning method, the xylem was injured with a pin $15 \mathrm{~cm}$ below the dendrometer fixed to the trunk once a month. Sample blocks including wounded tissues were obtained from the two sample trees cut down in late January, 1996, and xylem increment was measured from the cross-sectional observations.

The growth increment data obtained with the dendrometer indicated growth dormancy for the first three to five months (from January to March or May) once a year in all the sample trees, in which growth ring boundary-like features were observed. This boundary zone consisted of flattened wood fibers with thinner cell walls, axial parenchyma cells, and small diameter vessel elements. On the other hand, the results obtained with the pinning method showed only a vague dormancy around March each year. It seems that growth measurement with a dendrometer is more suitable for detecting the long-term growth rhythms of xylem, as compared with the pinning method. No correlation of the climatic data with xylem increment was found during the 3-year period.

S. OHTA ${ }^{1}$, M. FuJITA ${ }^{2} \&$ H. SAIKI ${ }^{2}$ : ${ }^{1}$ Institute of Wood Technology, Akita Prefectural College of Agriculture, 11-1 Kaieizaka, Noshiro, Akita 016-0876, Japan; ${ }^{2}$ Graduate School of Agriculture, Kyoto University, Kakyo-ku, Kyoto 606, Japan. - Disorder of cellulose microfibrillar orientation on the newly-formed secondary wall surfaces of coniferous tracheids. - (Poster) 
Arrangements of cellulose microfibrils on the newly-formed surfaces in the secondary walls in differentiating tracheids of three softwood species were investigated. High resolution replicas of these tracheid lumina were observed under a transmission electron microscope.

On the newly-formed surfaces, individual microfibrils were almost straight and only partly meandered, and a crossing structure occurred in all layers of secondary walls. Therefore, the textures of the surfaces were intricate, that is, their microfibrillar orientations showed some disorders.

A quantitative evaluation of these disorders in the series of secondary wall depositing tracheids showed that $S_{2}$-depositing surfaces had the highest, and $S_{1}$ had the lowest degree of microfibrillar orientation, and that in the course of $S_{2}$-depositing the microfibrils became more orderly oriented.

Byung-Dae Park ${ }^{1}$, Bernard RiedL ${ }^{1} \&$ Yoon Soo KiM ${ }^{2}:{ }^{1}$ Département des Sciences du Bois et de la Forêt, Centre de Recherche en Sciences et Ingénierie des Macromolecules (CERSIM), Faculté de Forestérie et Géomatique, Université Laval, SainteFoy, Québec, G1K 7P4, Canada; ${ }^{2}$ Department of Forest Products and Technology, Chonnam National University, Kwangju 500-757, Korea. - Anatomical characteristics of wood fibers for medium density fiberboard (MDF) manufacture. (Poster)

Anatomical characteristics of four different sources of wood fibers (eucalyptus, Italian poplar, hemlock, and mixed species fibers) were investigated to study the influence of anatomical aspects of these fibers on the performance of medium density fiberboard (MDF) panels bonded with both urea-formaldehyde (UF) and phenol-formaldehyde (PF) adhesives. Fiber length and its distribution, morphology, bulk density, and acidity of each fiber type were measured. Mechanical properties of MDF panels manufactured by the dry process using these different fibers were determined for the comparison of board performance. Eucalyptus and Italian poplar fibers had a large fraction of very short fibers which resulted in an increase of the fiber surface and resin consumption. In contrast, very long hemlock fibers with lower bulk density have caused difficulties in the fiber-mat forming process. MDF panels made from mixed species fibers showed the best performance with the highest internal bond (IB) strength of all panels prepared. As expected, UF-bonded MDF panels showed poor dimensional stabilities (thickness swelling and water absorption after 24 hours of soaking in cold water). In conclusion the present study suggested that the anatomical characteristics of wood fibers such as fiber length and its distribution seemed to be related with fiber bulk density that has influenced ultimately the performance of MDF boards.

SAng Jin Park \& Ki Ho Jung: Department of Wood Science \& Technology, College of Agriculture, Kyungpook University, Sankyuk-Dong, Taegu 702-701, Korea. Identification of Betula species in dry archaeological wooden plates, Tripitaka Koreana. - (Poster)

Tripitaka Koreana, the 81,258 wooden plates on which Buddhist scriptures were engraved, is one of the most renowned cultural properties of Korea. The species of 
wood used for the plates has been recorded as Betula sp. Recently, it was revealed that the plates consist of more than 10 different species including Prunus sp., Pyrus sp., and Betula sp. The identification of the species of the wooden plates may give us an opportunity to elucidate historical secrets of Tripitaka Koreana. It is especially important to identify four different species in the genus Betula (B. platyphylla var. japonica, B. costata, B. schmidtii, and B. davurica).

In order to identify the four Betula species that were used in the wooden plates, growth ring widths of the four different species were classified as $0.5,1.0,1.5,2.0$, 2.5, $3.0 \mathrm{~mm}$ and then features such as percentage area of pores and the diameter and thickness of vessel elements and fibers were measured using image analysis.

Average percentage area occupied by pores was $11 \%$ in Betula schmidtii, 20-22\% in B. costata and B. davurica, and $25 \%$ in B. platophylla var. japonica. Between 1-3 $\mathrm{mm}$ of the growth ring width, the percentage area of pores remains constant with increasing ring width. The relationship between the variation pattern of the percentage area of pores and growth ring width varies with species.

The proportion of solitary pores was $46 \%$ in Betula schmidtii, $36 \%$ in B. davurica, and $20 \%$ and $18 \%$ in B. costata and B. platophylla var. japonica, respectively. The cell wall thickness of fibers was thickest in Betula schmidtii, and decreased in the order of B. davurica, B. costata, and B. platophylla var. japonica. However, the difference between $B$. costata and $B$. platophylla var. japonica was small. Using the above information, we can identify the four species of the genus Betula.

Won-Kyu Park ${ }^{1}$, Eugene A. Vaganov ${ }^{2} \&$ Dmitri Ovtchinnikov': ${ }^{1}$ Department of Forest Products, Chungbuk National University, Cheongju 361-763, Korea; ${ }^{2}$ V.N. Sukachev Institute of Forest, Siberian Branch, Russian Academy of Sciences, Krasnoyarsk 660036, Russia. - Tracheid-diameter chronologies of Pinus densiflora and their relationships with climate. - (Paper)

Two cores from each of five Pinus densiflora Sieb. et Zucc. trees (about 65 years old), growing at a southern slope site (500 $\mathrm{m}$ a.s.1.) in the Walak National Park in central Korea, were sampled. Each core was mounted with glue on a wood stick and was smoothed with a surgical knife to obtain a cross-sectional surface. Fine contrast between cell wall and lumen was obtained by applying white chalk. For the annual rings of the 16-year period from 1975 to 1990, the radial diameters of each tracheid in 5 randomly chosen radial rows were measured using a measuring microscope. The tracheidogram, intra-annual plot of tracheid diameter, was prepared after standardizing the number of cells per row to 50. From the standardized tracheidogram, 5 cellsize chronologies were derived from year-to-year variations in tracheid diameter at five different positions in the ring, i.e., 2 nd, 15th, 30th, 40th, and 45th tracheids.

The correlations between cell-size chronology and climate (5-day mean temperature, and monthly precipitation and temperature) were examined. Negative correlations with temperature and positive ones with precipitation were found in 2nd- and 15 th-cell chronologies but not in the later ones. Inference about short-term, e.g. weekly, seasonal climate could be obtained from cell-size chronology using intra-annual measurements on tracheid diameter. 
Won-Kyu Park ${ }^{1}$, Eugene A. Vaganov ${ }^{2}$, Alex V. Shashkin ${ }^{2}$ \& Pattrawut Pusingha ${ }^{1}$ : ${ }^{1}$ Department of Forest Products, Chungbuk National University, Cheongju 361-763, Korea; ${ }^{2}$ V.N. Sukachev Institute of Forest, Siberian Branch, Russian Academy of Sciences, Krasnoyarsk 660036, Russia. - Influence of global warming on radial growth in Korean conifers: simulation models using intra-annual variations of tracheid dimensions. - (Poster)

Simulation models, which were developed to describe the inter-annual growth of trees by calculating the diameters of tracheids from daily climatic data, were tested for several Korean conifers. We calibrated and verified the model using ring-width chronologies. The results indicate good coincidence between actual and estimated data. The models also reveal what climatic factors and which interval of the season will mostly limit the growth rate and what we can expect if climatic conditions in the studied areas are changed. The climatic changes which include different seasonal scenarios, e.g. increasing temperature in spring, are expected to reduce the duration of optimal growth and rate of growth. Consequently, the trees are expected to suffer a radial increment loss of up to $30 \%$.

Nathsuda Pumijumnong ${ }^{1}$, Dieter Eckstein ${ }^{2}$, Ute Sass $^{2} \&$ Won-Kyu Park ${ }^{3}$ : ${ }^{1}$ Faculty of Environment and Resource Studies, Mahidol University, Salaya, Phutthamonthon, Nakhon Pathom 73170, Thailand; ${ }^{2}$ University of Hamburg, Ordinariat für Holzbiologie, Leuschnerstr. 91, D-21031 Hamburg, Germany; ${ }^{3}$ Department of Forest Products, College of Agriculture, Chungbuk National University, Cheongju 361-763, Korea. - The dendrochronologies network on teak (Tectona grandis) and its reconstruction. - (Poster)

The teak (Tectona grandis L.) dendrochronologies network on living trees and felled trees in northern Thailand was recently reviewed. They display the potential to provide continuous and long-term information about change both in the local climate of Thailand and in Southeast Asian monsoon circulation. The high correlation between all teak chronologies and temperature and rainfall processed at the beginning of the wet season was used to reconstruct the past climate. Multiple regression was employed for reconstructing monthly rainfall from April to July and monthly average temperature from May to July during these years for northern Thailand. Seven site chronologies were added in the calibration equation as predictor that all include the period from 1870 until 1990. Finally correlation was used to explain the relationship between teak chronologies and reconstruction. This study indicated that the growth of teak in northern Thailand is influenced by the amount of rain during the beginning of the wet period. The explained variance is over $60 \%$. The results suggest the potentials of teak tree-ring chronology for the reconstruction of the palaeomonsoon in Southeast Asia.

Nathsuda Pumijumnong ${ }^{1}$ \& Won-Kyu Park ${ }^{2}$ : ${ }^{1}$ Faculty of Environment and Resource Studies, Mahidol University, Salaya, Phutthamonthon, Nakhon Pathom 73170, Thailand; ${ }^{2}$ Department of Forest Products, College of Agriculture, Chungbuk National University, Cheongju 361-763, Korea. - Reconstruction of Southeast Asian monsoon using anatomical variables and teak tree rings. - (Paper) 
Anatomical characteristics of earlywood and latewood of teak (Tectona grandis L.) growing in northern Thailand show high correlations with precipitation and temperature variables. The ring-width chronology shows only correlations with precipitation. A regression equation incorporating earlywood vessel diameter and ring-width chronologies was used to reconstruct May-July precipitation. Latewood vessel density was used to reconstruct April-May temperature. Stepwise multiple regression is employed for calibration and could well be verified with independent data.

Hans Georg Richter ${ }^{1}$, Dietger Grosser ${ }^{2}$ \& Immo Heinz': ${ }^{1}$ Institute for Wood Biology and Wood Protection, Federal Research Centre for Forestry and Forest Products, Leuschnerstr. 91, D-21031 Hamburg, Germany; ${ }^{2}$ Instituite for Wood Research, University of Munich, Winzererstr. 45, D-80797 Munich, Germany. - Proposal for an IAWA List of Microscopic Features for Softwood. - (Paper)

With the preparation of the IAWA List of Microscopic Features for Hardwood Identification in 1987 (published in 1989) the need for a similar list for softwoods was discussed time and again. A provisional list of characters for softwood identification and accompanying character notes (definitions, comments, procedures, etc.) have now been elaborated in a cooperative effort between the wood research institutions at Hamburg and Munich, Germany. Taking into account the international trend towards computer-assisted wood identification systems (CAWIS), the list has been conceived in the DELTA (Description Language for Taxonomy) format, and a small database with coded descriptions of 30 coniferous taxa, complete with character and taxon illustrations, has been elaborated for test purposes. It is proposed to use this provisional list for discussion of an official 'IAWA List of Microscopic Features for Softwood Identification' to be elaborated by a special IAWA committee set up for this purpose. A brief demonstration of the database is being arranged upon request.

Katia Ruel: Centre de Recherches sur les Macromolécules Végétales (CERMAV), CNRS BP 53, 38041 Grenoble Cedex 09, France. - Topochemistry and microdiversity of lignin in plant cell walls. - (Paper)

The main lignin subunits could be visualized by transmission electron microscopy with antibodies raised against synthetic lignin model polymers. Thus, immunological probes against p-hydroxyphenyl propane, guaiacyl and mixed guaiacyl-syringyl units allowed to specifically localize the qualitative distribution of lignins in plant cell tissues. Depending on the mode of preparation of the synthetic lignin antigens, the corresponding antibodies showed specificity for condensed and noncondensed interunits linkages. This specificity is illustrated with the different labelling provided by the antibodies when applied to various wood and nonwoody materials. The results clearly show the heterogeneity of lignification between tissues but also demonstrates the microheterogeneity of lignin deposition within a single wood cell wall. Our immunological markers were successfully applied to differentiating tissues, transgenic plants in which lignin synthesis pathways had been modified, as well as in tissues from reaction wood. 
Mohd. Hamami Sahri ${ }^{1}$, Lathsamy Boupha ${ }^{2}$, Tadashi Nobuchi ${ }^{3}$ \& Mohd. ZiN JusoH $^{1}$ : ${ }^{1}$ Department of Forest Production, Faculty of Forestry, Universiti Putra Malaysia, Serdang, Selangor, Malaysia; ${ }^{2}$ Graduate Student, Faculty of Forestry, Universiti Putra Malaysia, Serdang, Selangor, Malaysia; ${ }^{3}$ Faculty of Agriculture, Kyoto University, Kyoto 606-01, Japan. - Wood quality assessment of plantation grown Azadirachta excelsa from Malaysia. - (Paper)

Azadirachta excelsa (Jack) Jacobs is a fast growing tree, with a tall and straight clear bole. Six planted A. excelsa trees of three growth rates (dominant, co-dominant and suppressed) under the same site conditions and the same age were sampled from Bukit Ari Forest Reserve, Kepong Selangor. For each tree, samples were taken from three height levels and radial positions to provide specimens for anatomical, physical and mechanical properties investigation between growth rates and within-tree variations. The tests were conducted in accordance to British Standard (BS 373, 1957).

Mean vessel, ray and fiber proportion were at $18.99 \%, 19.08 \%$ and $62.74 \%$, respectively. This species showed a mean fiber length of $1.12 \mathrm{~mm}$, fiber diameter of $24.17 \mu \mathrm{m}$, fiber lumen diameter of $11.55 \mu \mathrm{m}$, and fiber wall thickness of $6.31 \mu \mathrm{m}$. The mean specific gravity (SG) was 0.59 , within the range of the light hardwood group. The tangential, radial and volumetric shrinkages were $5.64 \%, 2.61 \%$ or $9.3 \%$, respectively. Mean shear strength parallel to the grain was $13.34 \mathrm{Mpa}$, compression strength parallel to the grain was $41.95 \mathrm{Mpa}$, and hardness value of $3.03 \mathrm{kN}$. The mean modulus of elasticity (MOE) and modulus of rupture (MOR) obtained from static bending strength were $6862 \mathrm{Mpa}$ and $83.85 \mathrm{Mpa}$ respectively. The anatomical, physical and mechanical properties of $A$. excelsa evaluated in this study were comparable to many of the light hardwood species. Therefore, the tree is suitable for a wide range of utilization.

Between growth-rate categories, variations of all properties analyzed showed significant differences. Dominant trees exhibited longer fibers, thicker fiber walls, higher specific gravity and strength properties than the co-dominant and suppressed trees. The considerable variations in specific gravity, in strength and in anatomical parameters among trees, if genetically controlled, offers possibilities for selection of breeding stock from seed or cuttings with desirable wood quality. Within-tree variation was more consistent in radial than in vertical direction, suggesting that diameter growth is a more important factor contributing to the variation than the height growth. Samples from the mid-point between the pith and the bark were found to have high specific gravity and were also more dimensionally stable. Results of this study showed that specific gravity provides the most valuable contributing factor to the strength of wood.

Yasuaki SaKamoto ${ }^{1} \&$ Yuzou SANO ${ }^{2}$ : ${ }^{1}$ Hokkaido Research Center, Forestry and Forest Products Research Institute, Hitsujigaoka 7, Toyohira-Ku, Sapporo 062-8516, Japan; ${ }^{2}$ Department of Forest Science, Faculty of Agriculture, Hokkaido University, Sapporo 060-8589, Japan. - Inhibition of water conductance of willow (Salix sachalinensis) infected with Erwinia salicis. - (Poster)

Recently, the watermark disease of willows (Salix spp.) caused by the bacterium Erwinia salicis was found in the mountain area of central Hokkaido - the northern island of Japan. The disease occurs only in England, Netherlands, and Belgium, and 
is now reported from Japan. During spring and summer, the leaves and branches suddenly wilted, turned reddish brown and died. Afterwards, some branches and trunks were killed. If the affected branches or trunks were cut through, the distinct, watery reddish brown or brownish black stained zone (watermark) was seen in the sapwood. The watermark appeared in loop or arc form. Anatomical study showed that some of the vessels in the watermark were plugged with tyloses and a mass of bacteria. The water absorption test with safranin O solution revealed that only newly formed sapwood had water conductance but the watermark had not in diseased trees. On the contrary, all the sapwood showed water conductance in healthy trees.

Yuzou Sano, Yasuhiro Utsumi \& Jun Ohtani: Department of Forest Science, Faculty of Agriculture, Hokkaido University, Sapporo 060-8589, Japan. - Seasonal changes in the structure of intervessel and vessel-parenchyma pit membranes in Fraxinus mandshurica var. japonica. - (Poster)

To elucidate the seasonal changes in the structure of pit membranes in the sapwood of Fraxinus mandshurica var. japonica, small wood blocks were sampled seasonally from late autumn to the next summer, and the pit membranes of various pit pairs were examined by field-emission scanning electron microscopy. Seasonal variation in the appearance of intervessel and vessel-parenchyma pit membranes were detected in the outer layer of the sapwood. In late autumn, when all the leaves had fallen, incrusting materials were present in all the intervessel pit membranes and vessel-side surfaces of vessel-parenchyma pit membranes of the current-year xylem. In the next early spring, when budbreak had not yet occurred, the superficial appearance of both the intervessel pit membranes and vessel-side surfaces of vessel-parenchyma pit membranes was similar to that in the previous year's autumn. In subsequent late spring, soon after the leaves had expanded, the incrusting materials were absent from both the intervessel pit membranes and vessel-side surfaces of vessel-parenchyma pit membranes in the latewood, whereas the incrusting materials were still present in those pit membranes in the ring-porous zone. From these results, it is possible that the intervessel pit membranes and vessel-side surfaces of vessel-parenchyma pit membranes are coated by incrusting materials around leaf fall. It is likely that, at the time of budbreak in spring, the incrusting materials disappear from the pit membranes in the latewood whereas they remain in the pit membranes of the ring-porous zone.

Uwe Schmitt $^{1}$, Adya P. Singh ${ }^{2}$, Othar Kordsachia ${ }^{1}$ \& Evelyn Pöhler ${ }^{3}$ : ${ }^{1}$ Federal Research Centre for Forestry and Forest Products, Leuschnerstr. 91, D-21027 Hamburg, Germany; ${ }^{2}$ New Zealand Forest Research Institute Ltd., Private Bag 3020, Rotorua, New Zealand; ${ }^{3}$ Swiss Federal Institute of Technology, ETH Zentrum, 8092 Zürich, Switzerland. - The topochemistry of delignification of Pinus radiata during ASAM pulping. - (Paper)

The delignification of Pinus radiata was investigated by chemical and microscopical analyses during pulping by the alkaline ASAM process (ASAM = alkaline sulfite / AQ /methanol-pulping). The cookings were done in an electrically heated seven-liter digester rotating overhead. The heating-up time to the maximum temperature of $180^{\circ} \mathrm{C}$ was 90 minutes, then the chips were cooked up to 180 minutes. At specific 
times, the cooking was stopped for sampling in order to obtain information on the progressive removal of lignin from the tracheid cell walls. Klason lignin was shown to decrease during the first 90 minutes of heating, from an initial content of $29.7 \%$ to $11.2 \%$. That means that more than $60 \%$ delignification occurred already in the heating-up phase. Samples taken after 180 minutes overall cooking time had $1.9 \%$ Klason lignin and a Kappa number of 22.2. The examination of ultrathin sections by transmission electron microscopy after staining with potassium permanganate clearly showed the distribution of lignin across the tracheid cell walls. This technique together with point analysis using UV microscopy at a wavelength of $280 \mathrm{~nm}$ revealed that the lignin content within the intercorner middle lamella and the $S_{2}$ layer reached a rather low level only after 75 and 90 minutes of cooking. At this stage, the axial tracheids appeared partly separated from each other. Some of them remained joined only at the cell corner areas, reflecting the presence of greater amounts of lignin there as compared with the intercorner middle lamella region. Separation of the tracheids became complete after 120 and 150 minutes of cooking. This work has shown that as compared with Pinus sylvestris and Picea abies, in Pinus radiata tracheids separation occurs earlier and also the Klason lignin content and Kappa number are lower for the same period of cooking. It can be suggested that Pinus radiata is a well suited raw material for the environmentally friendly ASAM pulping, the saving in time and energy being substantial.

S. Shirai, A. Yoshinaga \& M. Fujita: Division of Forest and Biomaterials Science, Graduate School of Agriculture, Kyoto University, Sakyo-ku, Kyoto 606-8502, Japan. - Ultrastructural observations on the suberized cell walls in periderm of Ginkgo biloba. - (Poster)

In the reports on the ultrastructure of suberized cell walls, there are serious disagreements on their lamellar appearance. To clarify the relationship between the chemical nature and ultrastructure of the suberized cell wall, we applied extraction and depolymerization on the periderms of Ginkgo biloba L., and observed them by polarized light microscopy, ultraviolet microspectrophotometry, and transmission electron microscopy (TEM).

Bark samples were sectioned at $50 \mu \mathrm{m}$ thickness. On these sections, extraction of waxes with a chloroform-methanol mixture and saponification of suberin with $2 \%$ $\mathrm{KOH}$ in ethanol were carried out. Treated and untreated sections were embedded in Spurr's medium or methacrilate resin. The embedded sections were further sectioned in $1 \mu \mathrm{m}$ for light microscopy and about $0.1 \mu \mathrm{m}$ for TEM. $\mathrm{KMnO}_{4}$ staining or platinum-carbon shadowing after de-embedding were performed for TEM observation.

With Sudan IV staining, it was confirmed that the suberized domain was located in the mid-layer of the phellem cell wall. This layer is to be called 'suberin layer'. The suberin layer had an absorption maximum at $320 \mathrm{~nm}$, and this absorption was not changed with solvent extraction but disappeared with $\mathrm{KOH}$ saponification. Therefore this absorption is probably due to the aromatic domain of suberin. Under polarized light, the birefringence of the suberin layer indicated that molecules of the suberin layer were arranged in radial direction of the cell. Because the birefringence was not changed through the solvent extraction, it is suggested that suberin molecules and not waxes are radially arranged in the cell wall. The solvent extraction did not affect the 
lamellar structure of the suberin layer in $\mathrm{KMnO}_{4}$ stained sections. In platinum-carbon shadowing, the lamellar structure was observed as a pile of sheets. Each sheet has almost the same thickness as the electron-opaque lamella observed in $\mathrm{KMnO}_{4}$ stained sections. These sheets are considered as polymeric suberin. The electron-translucent lamella may be the gaps between these sheets.

Adya P. Singh \& ARMando G. MCDonaLd: New Zealand Forest Research Institute Ltd., Private Bag 3020, Rotorua, New Zealand. - Comparison of radiata pine and rubberwood HTMP fibers by microscopy and MDF panel properties. - (Paper)

Features of commercially sourced HTMP fibers of radiata pine, a softwood, and rubberwood, a hardwood were characterized by transmission electron microscopy, other fiber properties and panel properties. Some important differences (fiber length, shives, extractives) were also observed between the fibers of radiata pine and those of rubberwood. The mechanical properties of panels made from both fibers were comparable. However, the water soak test showed that panels made from rubberwood had a 40\% lower thickness swell compared with pine. The surface of the fibers was highly variable for both radiata pine and rubberwood. The separation of radiata pine fibers occurred in the middle lamella region as well as in the boundary region between middle lamella and $S_{1}$ layer, exposing middle lamella and $S_{1}$ wall layer, respectively. In comparison, the separation of rubberwood fibers (or bundles of fibers) occurred almost always in the middle lamella. The fibers of the two types of wood also varied significantly in the way fractures took place in the middle lamella. In radiata pine the fractures were more regular exposing large areas of the middle lamella of a uniform thickness. The fractures in the middle lamella in rubberwood were highly irregular and consequently the thickness and the morphology of the exposed middle lamella varied greatly among fibers as well as within individual fibers in determining the properties of a MDF board and fiber bundles. In view of the importance of the characteristics of the surface of HTMP fibers it is hoped that this preliminary work will encourage further work to characterize fibers from different sources and prepared under different conditions.

Adya P. Singh ${ }^{1} \&$ Uwe Schmitr ${ }^{2}:{ }^{1}$ New Zealand Forest Research Institute Ltd., Private Bag 3020, Rotorua, New Zealand; ${ }^{2}$ Federal Research Centre for Forestry and Forest Products, Leuschnerstr. 91, D-21027 Hamburg, Germany. — High variability in the distribution of lignin in the middle lamella of rubberwood (Hevea brasiliensis). - (Paper)

Transmission electron microscopy of ultrathin sections of rubberwood cells, after staining with potassium permanganate, showed considerable variability in the extent of lignification and the pattern of lignin distribution in both cell corner and intercorner middle lamellae. The cell corner middle lamellae mostly had a mottled appearance, some parts being considerably denser than others. The intercorner middle lamellae also showed inhomogeneity in lignin distribution, although not to the same extent as the cell corner middle lamellae. UV microscopy was also undertaken to assess the extent of variability in the distribution of lignin in the various regions of the middle lamella. The patterns observed in rubberwood cells are discussed in relation to the significance of lignin inhomogeneity to wood product formation. 
Adya P. Singh ${ }^{1}$, Uwe SchmitT ${ }^{2}$, Yoon Soo KIM ${ }^{3}$ \& Bernard Dawson ${ }^{1}:{ }^{1}$ New Zealand Forest Research Institute Ltd., Private Bag 3020, Rotorua, New Zealand; ${ }^{2}$ Federal Research Centre for Forestry and Forest Products, Leuschnerstr. 91, D-21027 Hamburg, Germany; ${ }^{3}$ Department of Forest Products and Technology, Chonnam National University, Kwangju 500-757, Korea. - The knowledge of wood structure critical to understanding process performance. - (Paper)

The wood, a composite of lignocellulosic materials, is a natural product and a renewable resource. However, this resource is becoming increasingly scarce in many parts of the world because of excessive use in relation to its production, making it necessary in future to use wood wisely and more effectively. In this context, the need for better performing and longer lasting products from wood is widely recognized. For the development of high quality wood products and the products tailored to suit specific applications it is important to understand the structure of wood at all levels of its organisation, from macroscopic to molecular, so that product development is based on a sound knowledge of structure-process relationships. In this presentation, the importance of the detailed knowledge of wood structure in relation to the performance of the processes, which are aimed at specific wood products will be discussed with appropriate examples.

SyoJi Sudo: Timber Consultant, Kamikitazawa 4-31-3, Setagaya, Tokyo 156-0057, Japan. - A computerized key for hardwood identification: its significance in the a-century-old history of wood anatomy in Japan. - (Paper)

Since the first wood anatomical descriptions of softwood species were published for the purpose of identification more than a hundred years ago, there have been a number of publications on hardwood and softwood identification in Japan. Following a brief review of representative microscopical keys based on dichotomous, multiple entry and card sorting systems, a version of a computerized key for the identification of Japanese hardwood species is proposed. Applying the descriptors proposed by the IAWA Committee, an identification key for 240 Japanese hardwood species was prepared. Most of the descriptions were based on the author's observations with some reference to the previous reports. Some descriptors, particularly quantitative ones, were not applied as proposed by the IAWA Committee because of lack of sufficient data. This identification key is primarily aimed at computer-assisted identification, not as a complete database. To construct a complete database further observations and descriptions are needed.

M. Suzukr ${ }^{1}$, R. Hirano ${ }^{1}$ \& K. Yoda ${ }^{2}:{ }^{1}$ Botanical Garden, Faculty of Science, Tohoku University, Sendai 980-0862, Japan; ${ }^{2}$ Faculty of Science \&Technology, Ishinomaki Senshu University, Ishinomaki 986-0031, Japan. - Phenological analysis of wood formation in temperate deciduous ring and diffuse-porous wood. - (Paper)

Phenology and wood formation were compared in four deciduous diffuse-porous trees (Fagus crenata, Magnolia obovata, Prunus grayana and Cornus controversa) and four deciduous ring-porous trees (Castanea crenata, Quercus serrata, Zelkova serrata and Phellodendron amurense). Three mature trees of each species growing in natural secondary forest in Sendai were selected. From each tree, small cubic blocks 
of the outermost wood and inner bark with cambium were cut off with intervals of 1-3 weeks since March 22 to November 20 in 1995. At the same time of block sampling, a small branch was collected for measuring leaf area. Relative leaf area was used as a parameter of phenology.

Thin sections were observed by means of light microscopy under normal and polarized light. The first observation of tangentially enlarged cells on the xylem side near the cambium was regarded as the initiation of vessel formation. Presence of brilliant vessel walls under polarized light was regarded as completion of vessel formation. Presence of several layers of thick-walled fibrous cells and absence of developing cells between the fibrous cells and cambium was considered as sign of cambium dormancy.

In agreement with earlier studies, initiation of large vessel formation in ringporous wood was 6 to 4 weeks earlier than leaf budding, while that of diffuse-porous wood was 0 to 2 weeks after leaf budding. The first large vessels in ring-porous wood were completed around leaf budding $(-1$ to +1 week of budding), while the firstformed vessels of diffuse-porous wood were completed after the completion of leaf expansion ( 3 to 5 weeks after leaf budding). Small vessel formation in ring-porous wood was completed after the completion of leaf expansion ( 4 to 7 weeks after budding). Both types of wood entered dormancy at the time of leaf fall in autumn (about 30 weeks after budding).

Our results suggest that phenological wood formation of the small vessels (latewood pores) in ring-porous wood is equivalent of vessels of diffuse-porous wood, because both the first-formed small vessels in ring-porous wood and the first-formed vessels in diffuse-porous wood come to maturity at nearly the same time after the completion of leaf expansion. This may mean that diffuse-porous wood has no comparable elements to the large vessels in ring-porous wood. It is known that the large vessels in ring-porous wood are derived from overwintering cells that were formed before cambium entered dormancy in the previous autumn but had not yet differentiated. Early dicotyledons in the late Cretaceous are almost all diffuse-porous and ring-porous wood became relatively common during the Tertiary in the northern hemisphere. This means that the ring-porous condition has been derived from the diffuse-porous one and developed under the distinct seasonal climate in the northern hemisphere. We would like to suggest that the large vessels in ring-porous woods are a newly formed adaptive character to serve active transportation of water for rapid growth in early spring after dormancy in the cold severe winter.

AKIRA TAKAHASHI: Museum of Nature and Human Activities, Hyogo, 6 Yayoigaoka, Sanda 669-1546, Japan. - Climatic variation of ring-porosity in the wood of Mallotus japonicus (Euphorbiaceae). - (Poster)

Among broad-leaved trees, diffuse-porosity is the most common condition and ring-porous wood is only relatively common in trees growing in the temperate region of the northern hemisphere. As the trees with ring-porous woods belong to various remotely related clades, ring-porosity must have originated through parallel evolution when broad-leaved trees adapted to temperate climates. 
It is interesting to compare the structural differences and vessel formation between ring-porous wood and diffuse-porous wood. It has been reported that vessel formation patterns between ring-porous trees and diffuse-porous trees may be phenologically different in relation to the first water conduction. Thus the functional significance of ring-porosity is evident. However, it is not clear to what extent ring-porosity is genetically fixed. How is ring-porosity affected by ecological or climatic changes? In order to investigate this I choose Mallotus japonicus (Thunb.) Muell. which is a deciduous tree species with ring-porous or semi-ring-porous wood and is widely distributed from north-eastern Honshu, cool-temperate region, to Ryukyu Islands, subtropical region, in Japan. I will investigate to what extent climatic changes have an effect on the variation in the wood anatomy, particularly ring-porosity. Samples are collected from various places of Japan and investigated anatomically.

Ken' ICHI TaKahashi \& Mitsuo Suzuki: Botanical Garden, Faculty of Science, Tohoku University, Sendai 980-0862, Japan. - Wood structural diversity among early dicotyledons in the Cretaceous of Japan. - (Poster)

Fossil woods are common in the Cretaceous of Hokkaido, Japan. Since the Cretaceous Yezo Group is a marine deposit, the fossil woods are well preserved in calcareous nodules with ammonites and bivalves, based on which we can exactly identify the geological age of the woods. We have collected about 140 dicotyledonous woods from the Albian, Cenomanian, Turonian, Coniacian and Santonian. Only two samples of small size are from the Albian (the uppermost part of the Lower Cretaceous), these are the oldest records of dicotyledons in Japan.

All 140 dicotyledonous woods were diffuse-porous, and we classified them into seven distinct types. Among the seven types, wood assignable to Icacinoxylon, Plataninium and Paraphyllanthoxylon and woods similar to some genera of Lauraceae and Fagaceae are included. These types exhibit a great diversity of wood structure among the early dicotyledons in the Cretaceous of Japan.

Four of the seven types first appeared in the Cenomanian, and two in the Turonian while the age of the remaining type is not yet clear. As all types except the unknown one had originated by the Turonian, we inferred that the Cretaceous dicotyledons had diversified in wood structure by this age. Furthermore, this result suggests that dicotyledons had differentiated to a great extent in the mid-Cretaceous in East Asia.

Katsuhiko Takata ${ }^{1}$ \& Yasuhiko Hirakawa $^{2}{ }^{1}$ 'Department of Forest Products, Faculty of Agriculture, Kyushu University, Fukuoka 812-8581, Japan; ${ }^{2}$ Wood Quality Laboratory, Forestry and Forest Products Research Institute, Tsukuba Norin, P. O. Box 16, Ibaraki 305-0903, Japan. — Variation in tree-ring components among 16 provenances of Japanese larch. - (Paper)

Japanese larch (Larix kaempferi (Lamb.) Carr., syn. L. leptolepis Gord.) is an endemic species to the central area of Honshu island of Japan, where it is found as geographically isolated populations. In this study, seven tree ring components (mean density, earlywood density, latewood density, ring width, earlywood width, latewood width and latewood percentage) were determined by X-ray densitometry. Test specimens were taken from trees of 16 provenances felled at the Kano trial stand estab- 
lished in the natural distribution area of this species. The relations between seven tree ring components and the differences among 16 provenances were investigated to reveal and obtain basic knowledge relevant for tree breeding.

Mean density had a significant and positive correlation with latewood percentage and earlywood density. There were significant differences in mean density and latewood percentage among the provenances. These results suggested that some tree ring components are controlled genetically.

F.W. Telewski ${ }^{1}$, B.R. Strain ${ }^{2}$, R.T. Swanson ${ }^{1}$ \& J.M. Burns ${ }^{3}$ : ${ }^{1}$ W.J. Beal Botanical Garden, Department of Botany \& Plant Pathology, Michigan State University, East Lansing, MI 48824, USA; ${ }^{2}$ Department of Botany, Duke University, Durham, NC 27708, USA; ${ }^{2}$ Laboratory of Tree Ring Research, University of Arizona, Tucson, AZ 85721, USA. - Ring width and anatomical responses to long-term atmospheric $\mathrm{CO}_{2}$ enrichment in field grown loblolly pine. - (Paper)

Field grown loblolly pines (Pinus taeda L.) were grown under non-limiting nutrient conditions for four years, in either open top chambers (OTC) at ambient carbon dioxide concentration or within OTC with an enriched carbon dioxide atmosphere of +30 Pa carbon dioxide over ambient conditions or without OTC at ambient carbon dioxide concentration. Samples collected at the end of the third treatment year were subjected to anatomical analysis to determine changes in wood characteristics in response to carbon dioxide enrichment. At the end of the fourth year a second set of samples was harvested to determine ring width, wood specific gravity and wood density using X-ray densitometry. Enrichment with carbon dioxide failed to significantly alter the cell wall to cell lumen ratio within the third year latewood band formed in 1994. No significant differences were observed in the density of resin ducts or in the ratio of resin duct cross-sectional area to xylem area within the same growth ring. Carbon dioxide enrichment did significantly increase ring width for three of the four years compared to the ambient OTC control treatment. Total, extractive-free wood specific gravity (determined by displacement) was also increased by carbon dioxide enrichment. However, when determined as total sample wood density via X-ray densitometry, the higher density of enriched samples was not significantly different from the OTC ambient controls. The first two growth rings of enriched trees had significantly higher maximum latewood densities than ambient OTC controls. No significant differences were observed in the minimum earlywood density of individual growth rings between OTC treatments.

Noritsugu Terashima: 2-610 Uedayama, Tenpaku, Nagoya 468-0001, Japan.-Formation and ultrastructure of lignified plant cell walls. - (Paper)

The ultrastructure of lignified plant cell walls was studied by observing the process of cell wall differentiation by various nondestructive methods including radiotracer methods. The lignified plant cell walls are formed by successive deposition of cell wall polymers, pectic substances, hemicelluloses and cellulose, and finally lignin. The polysaccharides play a role as a template for formation of lignin macromolecules, because monolignols polymerize to polylignol in polysaccharides gels. Depending on the type, age, and morphological region of the differentiating cell, different kinds 
of monolignols are supplied to polysaccharide gels. As a result, the structure of lignin is heterogeneous with respect to monomer composition, inter-unit linkages, and association with polysaccharides. In an early stage of lignification, bulk type polymers are formed as globular molecules, which grow in the following stage by endwise addition of monolignol to form larger molecules. In the final stage, cross-linkages between endwise polylignols are formed to give a condensed endwise polymer. In the secondary wall, the lignin-hemicellulose complexes surround cellulose microfibrils to form a twisted honeycomb structure.

C. Tокон, K. Takabe \& M. FujiTa: Division of Forest and Biomaterials Science, Graduate School of Agriculture, Kyoto University, Kyoto 606-8502, Japan. - Cellulose synthesized by Acetobacter xylinum in the presence of cell wall polysaccharides. - (Poster)

In plant cell walls, nascent cellulose microfibrils are deposited in a sol-like layer of non-cellulosic polysaccharides and water. Acetobacter xylinum, which is often used as a model system of cellulose biosynthesis, was cultured in Hestrin-Schramm medium (control medium) and Hestrin-Schramm medium containing pectin (pectin medium), xylan (xylan medium) or mannan (mannan medium) for examining influences of these polysaccharides on cellulose microfibrils. Synthesized cellulose was investigated using a transmission electron microscope, an X-ray diffractometer and an FT-IR spectrometer.

Loose bundles of cellulose microfibrils are formed in xylan and mannan medium in contrast to the tightly assembled ribbons being produced in control and pectin medium. The PATAg method revealed that pectin, xylan and mannan would exist close to cellulose microfibrils because the microfibrils produced in the medium containing each polysaccharide were stained, while that in the control medium was not. $\mathrm{X}$-ray diffractometry showed that the cellulose microfibrils in control and pectin mediums had preferential orientation, though the addition of xylan or mannan brought about disordered fibrils, especially in mannan medium. FT-IR spectroscopy indicated that the addition of mannan induced a reduction of the triclinic crystal phase (cellulose Ia) in cellulose microfibrils. This means that mannan induces cellulose crystals to change from the algal-bacterial type to the cotton-ramie type. Xylan also induced a small change of the crystal phase, but pectin did not have any effect.

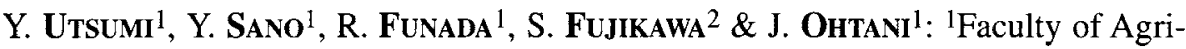 culture, ${ }^{2}$ Institute of Low Temperature Science, Hokkaido University, Sapporo 060- 8589, Japan. - Visualization of the progression of cavitation during the freeze- thaw cycle in Fraxinus mandshurica var. japonica by cryo-scanning electron microscopy. - (Poster)}

The progression of cavitation in earlywood vessels of Fraxinus mandshurica var. japonica during the course of freezing and subsequent thawing was investigated by cryo-scanning electron microscopy. Four-year-old trees, which were planted in pots, were used. The sample trees were put in a low temperature room kept at $-20^{\circ} \mathrm{C}$ and were allowed to freeze for 30 minutes. After four trees were sampled, the remainder was transferred to the laboratory for thawing. Then, two to four trees were sampled at 
intervals of one to six hours until twenty-four hours later. In the frozen samples, most earlywood vessels of the outermost annual ring were filled with water. This was also the case in trees which had been taken as control before freezing. In the thawed samples, however, many earlywood vessels of the outermost annual ring were cavitated and only some water droplets existed in the lumina of earlywood vessels. The percentage of cavitated vessels increased with time of thawing, and most vessels were cavitated after 24 hours. Earlywood vessels of the previous year's xylem had no water during this observation. These results indicated that the cavitation of earlywood vessels of the outermost annual ring of $F$. mandshurica var. japonica was caused by the freeze-thaw cycle and progressed during the thawing process.

Masahisa Wada \& TAKeshi OKano: Department of Biomaterials Science, Graduate School of Agricultural and Life Sciences, University of Tokyo, Bunkyo-ku, Tokyo 113-8657, Japan. - X-ray diffraction study of crystalline phase transition from cellulose I- $\alpha$ to $\beta$. - (Poster)

Crystalline phase transition from cellulose I-alpha to I-beta has been investigated by X-ray diffraction. X-ray diffraction of the highly crystalline I-alpha rich cellulose at the temperatures in the range of room temperature to $280^{\circ} \mathrm{C}$ was performed in an atmosphere of helium using PSPC (position sensitive proportional counter). $d$-Spacings of equatorial reflections increased with temperature, and the increasing rate above $230^{\circ} \mathrm{C}$ was conspicuously larger than the rate below $230^{\circ}$. It seems appropriate, therefore, that a temperature of $230^{\circ}$ is the phase transition point. This result corresponds well with our previous DSC result that the relaxation of the intermolecular hydrogen bond was induced at $230^{\circ}$. After cooling from $280^{\circ}$ to room temperature, the sample was mostly converted to the I-beta phase. The mechanism of cellulose I-alpha transition to I-beta via the high-temperature phase will be presented.

Seung Gon Wi, Kie-Pyo Lim \& Yoon Soo Kim: Department of Forest Products and Technology, Chonnam National University, Kwangju, Korea. - Inhomogeneous distribution of lignin in the middle lamella of compression wood. - (Poster)

Compression wood of Ginkgo biloba and Pinus densiflora was processed for the observation of lignin distribution using light microscopy (LM) and transmission electron microscopy (TEM). When compared to the secondary cell walls, the middle lamella in the compression wood showed different staining intensity with toluidin blue and potassium permanganate. In the TEM observation, some compression wood tracheids showed a higher contrast in the outer part of the $S_{2}$ layer than in the middle lamella after potassium permanganate staining. Some part of middle lamella appeared poorly to moderately stained. Areas with reduced staining occurred at numerous discrete sites within the middle lamella regions. An uneven staining pattern was also apparent after toluidine blue staining, indicating that lignin content in compression wood appeared to be concentrated in the outer part of the $S_{2}$ layer rather than in the middle lamella. UV micrographs of ultrathin sections with the microdensitometer also confirmed a high UV-absorption at the outer part of the $\mathrm{S}_{2}$ layer in the compression wood. The microscopical studies strongly suggested that the distribution of lignin in the middle lamella of the compression wood was not even and highly variable. 
Andrew Wong ${ }^{1}$, Raymond B. Pearce ${ }^{2}$, Geoff W. Grime ${ }^{3}$, Frank WatT $^{4} \&$ Salamah SElAMAT: ${ }^{1}$ Forest Research Institute Malaysia, Kepong, Selangor 52109, Kuala Lumpur, Malaysia; ${ }^{2}$ School of Biological Sciences, University of Birmingham, Edgbaston, Birmingham BT15 2TT, United Kingdom; ${ }^{3}$ Scanning Microprobe Facility, University of Oxford, Keble Road, Oxford OX1 3RH, United Kingdom; ${ }^{4}$ Nuclear Microscopy Group, Physics Department, National University of Singapore, Kent Ridge, Singapore 119260. - Nuclear microscopy study on micro-analysis of copperchrome-arsenic preservative treated Malaysian hardwoods. - (Paper)

The novel nuclear microscopy, essentially Particle-induced X-ray Emission (PIXE) system, was applied for examining the macro-distribution and micro-analysis of copper-chrome-arsenic (CCA) preservative in the Malaysian hardwoods Koompassia malaccensis, $K$. excelsa, Alstonia spp. and Dipterocarpus spp., and one temperate pinewood, Pinus sylvestris, where the preservative retentions differed between these wood species. Results demonstrated that the pattern of preservative macro-distribution and the relative quantities of the constituent elements copper, chromium and arsenic deposited among the parenchymatous tissues, cell walls of vessels, fibers and tracheids in these timbers support the general observations in timbers using electroninduced X-ray emission (EIXE) coupled with electron microscopy. However, the considerably greater analytical sensitivity of PIXE, among other advantageous characteristics of the system, would make it a potentially attractive tool for wood preservation research.

Kana Yamashita, NaOKi OKada \& KoICHI Kamo: Forestry and Forest Products Research Institute, Tsukuba Norin, P.O. Box 16, Ibaraki 305-8687, Japan. - Investigation of radial growth of Cryptomeria japonica by the pinning method. - (Poster)

The pinning method was applied to investigate seasonal radial growth of Cryptomeria japonica D. Don. Radial growth in the four cardinal directions (North, East, South and West) of each tree was measured on 4 trees at 2-week intervals for 2 annual growth seasons, in 1996 and 1997.

The radial growth rate varied among the four directions within each tree and among trees. The transition from earlywood to latewood was initiated in June, July and August, and cell division ceased in August, September and October.

The variation of radial growth appeared to reflect the difference in the period of earlywood formation and the difference of the tracheids produced in June, July and August.

KoH YASue 1 , Ryo Funada ${ }^{2}$ \& Jun OHTANi ${ }^{2}$ : ${ }^{1}$ Wood Quality Laboratory, Forestry and Forest Products Research Institute, Tsukuba Norin, P.O. Box 16, Ibaraki 3058687, Japan; ${ }^{2}$ Department of Forest Science, Faculty of Agriculture, Hokkaido University, Sapporo 060-8589, Japan. - Dendroclimatological reconstruction in northern Hokkaido, Japan. - (Poster)

Tree-ring width and maximum density of Picea glehnii Mast. and Fraxinus mandshurica Rupr. var. japonica Maxim. were used to reconstruct the past climate in northern Hokkaido, Japan, where little dendroclimatological work has been done so far. A total of 7 chronologies ranging from 243 to 432 years were developed; both ring-width and 
maximum-density chronologies of $P$. glehnii at three sites and a ring-width chronology of $F$. mandshurica var. japonica at one site. Before calibration of the climate reconstruction model, we examined the effects of climatic factors on the parameters of tree rings. Response function and correlation analyses revealed that the ring width of P. glehnii is related mainly to local monthly temperature, but the responses differ among the sites. By contrast, the maximum densities are positively correlated with temperature during the current summer and negatively correlated with precipitation in current August at all sites. The ring width of $F$. mandshurica var. japonica is positively correlated with the temperature of current July and precipitation of current May. The relationships between maximum density of $P$. glehnii and tracheid dimensions demonstrated that the variations in maximum density were due to changes in the cell wall thickness of last formed tracheids that were influenced by the climate in late summer. These observations suggest that both maximum density of $P$. glehnii and ring-width of $F$. mandshurica var. japonica are suitable indicators for reconstruction of the climate in past summers.

The reconstruction models for both summer (June-September) temperature and August precipitation were calibrated and statistically verified. The summer temperature and August precipitation in northern Hokkaido were reconstructed back to A.D. 1750.

Kiyotsugu Yoda ${ }^{1}$, Mino Kikuchi ${ }^{1}$, Mitsuo Suzuki ${ }^{2} \&$ Hitoshi Suzuki ${ }^{1}:{ }^{1}$ School of Science and Engineering, Ishinomaki Senshu University, Miyagi, 986-8580, Japan; ${ }^{2}$ Botanical Garden, Faculty of Science, Tohoku University, Sendai 980-0862, Japan. - Annual diameter changes of the stem of a Zelkova serrata sapling. (Paper)

Previously we reported that a tree changed its trunk diameter more dynamically than had been expected (Yoda et al. 1996). To clarify how this kind of diameter change progresses according to the seasonal growth of tree species, the stem diameter of three parts (upper, middle and base) of a Zelkova serrata sapling were measured over a year using originally developed dendrometers. The stem started its thickening growth early in May, which was a few weeks later than budbreak. This thickening growth continued about five months until late in September. The thickening growth curve was flat in the other seven months, which means that thickening growth had ceased. In all three measuring points, spike-like diameter changes with duration times of seconds-to-minutes were observed, superimposed on the thickening growth. These spike-like changes occurred independently among the three measuring points. The frequency of these spike-like changes became high within about a month before budbreak, and decreased after the initiation of thickening growth. In the basal part of the stem, spike-like changes occurred throughout a year. In the other two parts, however, no spike-like changes were observed through a few weeks or months from autumn to winter. These results indicate that a certain kind of morphological and/or physiological internal phenomenon may be associated with spike-like changes in the sapling stem of Zelkova serrata, in which this phenomenon notably preceded budbreak and showed independent behavior among different parts of the stem. 
Arata Yoshinaga, Kohei Akiyoshi \& Minoru Fujita: Division of Forest and Biomaterials Science, Graduate School of Agriculture, Kyoto University, Sakyo-ku, Kyoto 606-8502, Japan. - Secondary wall thickening and lignification of xylem components in Betula grossa and Aesculus turbinata. - (Paper)

To clarify the origin of the heterogeneous distribution of guaiacyl (G) and syringyl (S) lignins, processes of secondary wall thickening and lignification were traced in two Japanese hardwoods which showed a different composition of $\mathrm{G}$ and $\mathrm{S}$ lignins.

A tree of Betula grossa and an Aesculus turbinata tree were felled in July and August. Lignification was traced using ultraviolet microscopic spectrophotometry with thin sections of differentiating xylem. Thickness of the same sections was evaluated by atomic force microscopy. Changes in cell wall thickness during differentiation were measured and the formation of cell wall layers was observed by polarizing light microscopy and transmission electron microscopy. To investigate the composition of $\mathrm{G}$ and $\mathrm{S}$ lignins in two species, oxidation products after nitrobenzene oxidation were quantitatively determined by gas chromatography and the syringaldehyde/vanillin molar ratio (S/V ratio) was calculated.

As the result of nitrobenzene oxidation, S/V ratios in Betula grossa and Aesculus turbinata were 3.2 and 2.2, respectively. The walls of wood fibers in Betula showed a stronger red purple color in the Mäule reaction than those of wood fibers in Aesculus. Thus the fiber walls in Betula were considered to be richer in syringyl lignin than those of Aesculus. Subsequently secondary wall thickening and lignification in wood fibers were compared.

In Aesculus, secondary wall thickening progressed rapidly and lignification progressed during a relatively long period after the thickening had been completed. In contrast, secondary wall thickening of wood fibers in Betula progressed rapidly in the early stage and then slowly in the later stage, and lignification progressed slowly in the later stage of thickening and was completed a little after the $S_{3}$ layers were formed.

Nobuo Yoshizawa ${ }^{1}$, Futoshi Ishiguri ${ }^{1}$, Minoru Andoh ${ }^{1}$, Shinso Yokota $^{1}$ \& TAKESHI FuRUNO ${ }^{2}$ : 1 Department of Forest Science, Faculty of Agriculture, Utsunomiya University, Utsunomiya 321-8505, Japan; ${ }^{2}$ Department of Natural Resources Process Engineering, Faculty of Science and Engineering, Shimane University, Matsue 6908504, Japan. - Improvement of wood quality by rupture of pit membranes in Japanese ceder, sugi (Cryptomeria japonica) logs by smoke-heating with increased far-infrared radiation. - (Poster)

A furnace for smoke-heating logs, with increased far-infrared radiation (FIR), was produced to improve wood quality. Green sugi (Cryptomeria japonica) logs with bark were smoke-heated by this system. In a short time, this process increased the temperature inside the logs up to $80-100^{\circ} \mathrm{C}$ uniformly, without any damage to the wood. The great increase in steam pressure inside the log resulted in the rupture of pit membranes (PMs) of tracheid bordered pits with a high frequency (about 50\% and $70 \%$ for heartwood and sapwood, respectively), leading to a decrease in the moisture contents of the logs. It is considered that the homogeneous distribution of moisture within a log inhibited the generation of drying stress and, as a result, any damage inside the logs did not occur. It was found that rupture of PMs occurs when a temperature of 
$80^{\circ} \mathrm{C}$ is attained inside the log. The rupture proceeded from the outer sapwood towards the pith, accompanied by the radiation heat transfer within the log. Through the rupture of PMs, smoke-heated sugi wood showed a large improvement in permeability. In addition, a reduction in residual stress in logs was achieved by the smokeheating of about 35 hours at a temperature inside the logs of more than $80^{\circ} \mathrm{C}$ without affecting the mechanical wood properties.

\section{(Late contribution)}

Seyyed Ziaeddin Hosseini \& Ali Rafighi, College of Wood \& Paper Engineering, University of Agricultural \& Natural Resources, P.O. Box 49175-634, Gorgan, Iran. - Primary investigation on the influence of altitude on juvenile wood rate production and fiber length in Iranian beech (Fagus orientalis L.). - (Paper)

The mean fiber length in Iranian beech wood (Fagus orientalis) at two altitudes in the Caspian forest, 501-1000 and 1001-1500 m above sea level, were randomly measured as 1.23 and $1.30 \mathrm{~mm}$, respectively. For papermaking purposes the average exploitation age at the two mentioned altitudes was calculated at 26 and 24 years on the basis of $20 \%$ juvenile wood in the stem.

These results showed that the mean fiber length at the higher elevation was better than at the lower one, but in contrast the lower average exploitation age was found at the higher elevation. This corresponds with more juvenile growth at the higher altitude. However, the observed differences in fiber length and exploitation age were not statistically significant. 